\title{
Cost-effectiveness of vaccination of immunocompetent older adults against herpes zoster in the Netherlands: a comparison between the adjuvanted subunit and live-attenuated vaccines
}

\author{
Pieter T. de Boer ${ }^{1,2^{*}}$, Alies van Lier ${ }^{1}$, Hester de Melker ${ }^{1}$, Albert J. M. van Wijck ${ }^{3}$, Jan C. Wilschut ${ }^{4}$,
} Albert Jan van Hoek ${ }^{1,5}$ and Maarten J. Postma $2,6,7$

\begin{abstract}
Background: The newly registered adjuvanted herpes zoster subunit vaccine ( $\mathrm{HZ} / \mathrm{su}$ ) has a higher efficacy than the available live-attenuated vaccine (ZVL). National decision-makers soon need to decide whether to introduce $\mathrm{HZ} / \mathrm{su}$ or to prefer $\mathrm{HZ} / \mathrm{su}$ above $\mathrm{ZVL}$.

Methods: Using a Markov model with a decision tree, we conducted a cost-effectiveness analysis of vaccination with $\mathrm{HZ} / \mathrm{su}$ (two doses within 2 months) or zoster vaccine live (ZVL) (single dose, or single dose with a booster after 10 years) for cohorts of 50-, 60-, 70- or 80-year-olds in the Netherlands. The model was parameterized using vaccine efficacy data from randomized clinical trials and up-to-date incidence, costs and health-related quality of life data from national datasets. We used a time horizon of 15 years, and the analysis was conducted from the societal perspective.
\end{abstract}

Results: At a coverage of 50\%, vaccination with two doses of HZ/su was estimated to prevent 4335 to $10,896 \mathrm{HZ}$ cases, depending on the cohort age. In comparison, this reduction was estimated at 400-4877 for ZVL and 4276466 for ZVL with a booster. The maximum vaccine cost per series of HZ/su to remain cost-effective to a willingnessto-pay threshold of $€ 20,000$ per quality-adjusted life year (QALY) gained ranged from $€ 109.09$ for 70-year-olds to $€ 63.68$ for 50-year-olds. The cost-effectiveness of ZVL changed considerably by age, with corresponding maximum vaccine cost per dose ranging from $€ 51.37$ for 60 -year-olds to $€ 0.73$ for 80 -year-olds. Adding a ZVL booster after 10 years would require a substantial reduction of the maximum cost per dose to remain cost-effective as compared to ZVL single dose. Sensitivity analyses on the vaccine cost demonstrated that there were scenarios in which vaccination with either $\mathrm{HZ} / \mathrm{su}$ (two doses), ZVL single dose or ZVL + booster could be the most cost-effective strategy.

\footnotetext{
*Correspondence: pieter.de.boer@rivm.nl; p.t.de.boer@rug.nl

'Centre for Infectious Disease Control, National Institute for Public Health and the Environment, Antonie Van Leeuwenhoeklaan 9, 3721 MA Bilthoven, The Netherlands

2Unit of PharmacoTherapy, -Epidemiology \& -Economics (PTE2), University of Groningen, Groningen Research Institute of Pharmacy, Groningen, The Netherlands

Full list of author information is available at the end of the article
}

(c) The Author(s). 2018 Open Access This article is distributed under the terms of the Creative Commons Attribution 4.0 International License (http://creativecommons.org/licenses/by/4.0/), which permits unrestricted use, distribution, and reproduction in any medium, provided you give appropriate credit to the original author(s) and the source, provide a link to the Creative Commons license, and indicate if changes were made. The Creative Commons Public Domain Dedication waiver (http://creativecommons.org/publicdomain/zero/1.0/) applies to the data made available in this article, unless otherwise stated. 
(Continued from previous page)

Conclusions: A strategy with two doses of $\mathrm{HZ} / \mathrm{su}$ was superior in reducing the burden of $\mathrm{HZ}$ as compared to a single dose or single dose + booster of ZVL. Both vaccines could potentially be cost-effective to a conventional Dutch willingness-to-pay threshold for preventive interventions. However, whether HZ/su or ZVL would be the most costeffective alternative depends largely on the vaccine cost.

Keywords: Herpes zoster, Cost-effectiveness, Vaccination, Post-herpetic neuralgia, Subunit vaccine, Live-attenuated vaccine

\section{Introduction}

Herpes zoster (HZ) is a painful, itchy, vesicular rash with a characteristic dermatomal distribution. It is caused by the reactivation of latent varicella-zoster virus (VZV), previously introduced during primary infection (varicella) [1]. In the Netherlands, where varicella vaccination has not been implemented, over $95 \%$ of the population is infected with VZV before the age of 6 years [2]. The average incidence of $\mathrm{HZ}$ in the Netherlands was 520 per 100,000 person-years in the period 2012-2015, and older age and a compromised immune system are the most important risk factors $[1,3,4]$. However, given the ageing population, it is expected that the incidence of $\mathrm{HZ}$ will increase in the near future [5]. Persistent pain, labelled post-herpetic neuralgia (PHN), is the most common complication of $\mathrm{HZ}$ occurring in $3-19 \%$ of the patients $[1,6,7]$. PHN might persist for years and is associated with significant interference with daily life activities $[8,9]$.

Besides the prevention by vaccination, therapeutic options for $\mathrm{HZ}$ and $\mathrm{PHN}$ are scarce. Therefore, several countries, including the United Kingdom (UK) and United States (US), have introduced HZ vaccination for older adults using the existing live-attenuated vaccine (zoster vaccine live [ZVL] or Zostavax ${ }^{\circledR}$ ), which has been registered in 2006 and was the only available vaccine at the time of introduction of vaccination in the UK/US. ZVL contains the live-attenuated OKA VZV strain and is registered for immunocompetent adults aged $\geq 50$ years [10]. A large randomized clinical trial among older adults aged $\geq 60$ years showed that a single dose of $\mathrm{ZVL}$ was 51\% (95\% confidence interval [95\% CI] 44-58\%) efficacious against $\mathrm{HZ}$ and $67 \%$ (95\% CI 48-79\%) against PHN [11]. However, efficacy against $\mathrm{HZ}$ was limited in the eldest age groups (38\% [95\% CI 25-48\%] among $\geq$ 70-year-olds), and a long-term follow-up study demonstrated that protection had completely waned within 10 years [12]. Therefore, several countries, including the Netherlands, decided against the use of ZVL in a public programme [13]. Nowadays, several post-licensure studies have confirmed the safety and effectiveness of ZVL. However, the decline of effectiveness with increasing age was less evident in post-licensure studies as compared to the clinical trial [14-17].
A new adjuvanted $\mathrm{HZ}$ subunit vaccine $(\mathrm{HZ} / \mathrm{su}$ or Shingrix ${ }^{\oplus}$ ) might potentially overcome the shortcomings of ZVL. In Europe, $\mathrm{HZ} / \mathrm{su}$ has been registered for all adults aged $\geq 50$ years in 2018 and is a recombinant vaccine containing the VZV glycoprotein $\mathrm{E}$ adjuvanted with the $\mathrm{ASO}_{\mathrm{B}}$ system [18]. The vaccine has been developed to be given in a two-dose schedule given 2-6 months apart. Two large randomized clinical trials have demonstrated that the protective efficacy of two doses $\mathrm{HZ} / \mathrm{su}$ against $\mathrm{HZ}$ incidence was 97\% (95\% CI 94-99\%) among immunocompetent $\geq 50$-year-olds and 91\% (95\% CI $87-95 \%)$ among $\geq 70$-year-olds $[19,20]$. The duration of protection is currently unknown, but the trial confirmed a relative stable efficacy over 4 years of follow-up [20].

Due to the registration of $\mathrm{HZ} / \mathrm{su}$, governments have the option to reassess their vaccination policy for $\mathrm{HZ}$ in the near future, but cost-effectiveness analyses for $\mathrm{HZ} / \mathrm{su}$ are yet scarce. Previous cost-effectiveness studies for the US, Hong Kong and Germany exist [21-24]; however, results from other countries are not directly transferable to the Dutch context due to potential differences in epidemiological conditions, existing vaccination policies against $\mathrm{HZ}$ and varicella, healthcare resource use and relative prices. Moreover, no comparison of $\mathrm{HZ} / \mathrm{su}$ with $\mathrm{ZVL}$ booster strategies has been performed, and a lack of studies incorporating real-world effectiveness data for ZVL is noticed. Therefore, we conducted a cost-effectiveness analysis of $\mathrm{HZ}$ vaccination for the Dutch setting. First, we compared the impact of $\mathrm{HZ} / \mathrm{su}$ and $\mathrm{ZVL}$ in immunocompetent older adults using efficacy data from the original vaccine trials, and we included a booster alternative for ZVL as well. Next, we analysed the threshold cost-effectiveness of $\mathrm{HZ}$ vaccination by seeking the maximum vaccine cost allowed to remain below $€ 20,000$ per quality-adjusted life year (QALY) gained, which is the conventional cost-effectiveness threshold for vaccination in the Netherlands [25]. As the burden of $\mathrm{HZ}$ and vaccine efficacy against $\mathrm{HZ}$ depends on age, we studied $\mathrm{HZ}$ vaccination for different vaccination ages and explicitly addressed the use of ZVL post-licensure real-world effectiveness data in a sensitivity analysis. 


\section{Methods}

\section{Overview}

A static Markov model connected with a decision tree (Additional file 1: Figure S1) was developed in Microsoft Excel 2010 (Microsoft Corporation, Redmond, WA, USA) to quantify the costs and health effects (in QALYs) of vaccination of Dutch older adults against $\mathrm{HZ}$ from a societal perspective. We used a static model, as $\mathrm{HZ}$ is a reactivation of an existing VZV infection, and no impact on transmission dynamics like herd effects is expected. Studied alternatives were (i) no vaccination (current situation), (ii) vaccination with $\mathrm{HZ} / \mathrm{su}$ (two doses within 2 months) and (iii) ZVL (single dose) and (iv) ZVL (single dose with a booster after 10 years). We used a 10-year period for the booster, as an immunogenicity study showed that a booster after this period is safe and provokes a similar immunological response as a first dose [26]. In the Markov model, cohorts were followed in annual cycles with an age maximum of 110 years. In each cycle, participants had the probability to stay alive or die due to another cause. Individuals who remained alive entered the decision tree, having the possibility to develop HZ, which subsequently could lead to hospitalization and/or death. We studied cohorts of $50,60,70$ and 80 years of age. Due to the high uncertainty around the long-term efficacy of $\mathrm{HZ} / \mathrm{su}$, we limited the time horizon to 15 years in the base case analysis (for instance from 70 to 85 years of age). We chose this conservative time horizon to do justice to the low level of decline of $\mathrm{HZ} / \mathrm{su}$ efficacy within the trial period but also to avoid overvaluation of the impact of vaccination among this older cohort by using a lifetime time horizon. According to the Dutch cost-effectiveness guidelines, future costs and QALYs were annually discounted by $4 \%$ and $1.5 \%$, respectively [27].

\section{Epidemiology}

Epidemiological inputs are shown in Table 1. Actual cohort sizes per January 1, 2017, and background mortality rates were obtained from Statistics Netherlands [28, 29]. The average incidence of $\mathrm{HZ}$ by age over the period 2012-2015 came from the NIVEL primary care database, a GP surveillance system covering approximately $0.7 \%$ of the Dutch population [3, 30]. We adjusted these rates for possible misdiagnoses by setting the proportion of false-positive diagnoses at $10.0 \%$ (95\% CI 7.9-12.4\%) [31]. Average incidence rates of $\mathrm{HZ}$ hospitalizations and 1-day hospital admissions by age over the period 20122014 were retrieved from the Dutch Hospital Data database, covering $80 \%$ of the population in 2012-2013 and $90 \%$ of the population in 2014 [32, 33]. Only admissions with a main diagnosis of $\mathrm{HZ}$ (International Statistical Classification of Diseases and Related Health Problems
[ICD] code B02) were used. The incidence of HZ-related mortality by age was based on the number of $\mathrm{HZ}$ death registries (ICD-code B02) over the period 2009-2015, obtained from Dutch national death registries that contain the cause of death of $98.5 \%$ of the deaths [34]. We adjusted the mortality rates according to a validation study on HZ coding of death registries in the US, indicating that $\mathrm{HZ}$ was not the true underlying cause of death in $47.5 \%(95 \%$ CI $32.0-63.0 \%)$ of the deaths assigned to $\mathrm{HZ}$ [35].

\section{QALY loss}

The QALY loss per HZ case was calculated by multiplying the time spent in a certain health state by the reduction of health-related quality of life (HR-QoL), i.e. disutility, associated with that health state and is shown in Table 1. For this calculation, we distinguished four health states of $\mathrm{HZ}$, i.e. no pain, mild pain, moderate pain and severe pain. The proportion of patients in each health state over time was estimated using a Dutch prospective cohort study that followed HZ patients aged $\geq$ 50 years over a maximum period of 12 months [6]. Disutilities by health state over time were obtained from the same study and were based on the validated three-level version of the Euroqol-5 dimensions (EQ-5D-3L) instrument. As severity and duration of pain showed to increase by age, separate analyses were done for the age groups $50-59$ years and $\geq 60$ years. Patients with moderate or severe pain after 3 months were defined as PHN patients. We found that the risk of PHN was estimated at $2.2 \%$ for 50 - to 59 -year-olds and $7.3 \%$ for $\geq 60$-year-olds. More details can be found in Additional file 1. Life years (LY) lost due to HZ-related premature mortality were estimated using life tables and were converted to QALYs lost using age-specific EQ-5D-3 L population norms from the Netherlands [36]. We ignored QALY losses due to vaccine-related adverse events in our base case analysis, as both $\mathrm{HZ} / \mathrm{su}$ and $\mathrm{ZVL}$ only caused short-term symptoms, and the impact on HR-QoL was not investigated $[11,19]$.

\section{Costs}

HZ-related costs per case are shown in Table 1. All costs were adjusted to the 2017 price year using the Dutch national consumer price index [37]. Costs per HZ case were estimated using the same prospective cohort study that was used to estimate HZ-related QALY losses [6]. In this study, the number of GP visits, specialist referrals, medication use and productivity loss was asked at different time points and were then converted to costs per case using standardized cost per item. Costs per hospital admission were based on the length of stay of admissions having $\mathrm{HZ}$ as main a diagnosis (ICD-code B02) over the period 2012-2014, and cost of a 1-day visit was 
Table 1 Model inputs of the analysis. In the probabilistic sensitivity analysis, the parameter inputs were simultaneously varied within the lower and upper estimates according to the distribution shown. In the deterministic sensitivity analysis, the parameter inputs were varied one-by-one between lower and upper inputs, while the "scenario" column shows inputs based on other plausible assumptions or sources

\begin{tabular}{|c|c|c|c|c|c|c|}
\hline Variable & Base case & Lower & Upper & Distribution & Scenario & Reference (base case/scenario) \\
\hline \multicolumn{7}{|l|}{ Demography } \\
\hline Cohort size & & & & & & Statistics Netherlands [29] \\
\hline 50 years & 253,491 & & & & & \\
\hline 60 years & 222,845 & & & & & \\
\hline 70 years & 217,058 & & & & & \\
\hline 80 years & 93,547 & & & & & \\
\hline Background mortality & Age-specific & & & & & Statistics Netherlands [28] \\
\hline \multicolumn{7}{|l|}{ HZ epidemiology } \\
\hline $\begin{array}{l}\text { HZ incidence per 100,000 } \\
\text { person-years }\end{array}$ & & & & & & \multirow{5}{*}{$\begin{array}{l}\text { NIVEL [30]/incidence adjusted for } \\
\text { immunocompetent population using } \\
\text { Schroder [4] }\end{array}$} \\
\hline $50-59$ years & 591 & 575 & 607 & Beta & 461 & \\
\hline $60-69$ years & 857 & 835 & 878 & Beta & 669 & \\
\hline 70-79 years & 1190 & 1157 & 1222 & Beta & 929 & \\
\hline$\geq 80$ years & 1481 & 1435 & 1527 & Beta & 1156 & \\
\hline $\begin{array}{l}\text { False positive } \mathrm{HZ} \\
\text { diagnoses (\%) }\end{array}$ & 10.0 & 7.9 & 12.4 & Beta & 0 & Van Hoek [31]/assuming no false positives \\
\hline $\begin{array}{l}\text { HZ hospitalization } \\
\text { incidence per 100,000 } \\
\text { person-years }\end{array}$ & & & & & & \multirow[t]{5}{*}{$\begin{array}{l}\text { Dutch Hospital Data [32]/incidence adjusted } \\
\text { for the immunocompetent population using } \\
\text { Hobbelen [49] }\end{array}$} \\
\hline $50-59$ years & 2.5 & 2.1 & 2.9 & Beta & 2.2 & \\
\hline $60-69$ years & 4.9 & 4.3 & 5.5 & Beta & 4.3 & \\
\hline 70-79 years & 9.5 & 8.4 & 10.6 & Beta & 8.3 & \\
\hline$\geq 80$ years & 18.4 & 16.4 & 20.4 & Beta & 16.1 & \\
\hline $\begin{array}{l}\text { HZ 1-day hospital admission } \\
\text { incidence per } 100,000 \\
\text { person-years }\end{array}$ & & & & & & \multirow[t]{5}{*}{$\begin{array}{l}\text { Dutch Hospital Data [32]/incidence adjusted } \\
\text { for the immunocompetent population using } \\
\text { Hobbelen [49] }\end{array}$} \\
\hline 50-59 years & 3.6 & 3.1 & 4.0 & Beta & 3.1 & \\
\hline 60-69 years & 9.6 & 8.8 & 10.5 & Beta & 8.4 & \\
\hline 70-79 years & 21.8 & 20.1 & 23.4 & Beta & 19.1 & \\
\hline$\geq 80$ years & 28.2 & 25.8 & 30.7 & Beta & 24.8 & \\
\hline $\begin{array}{l}\text { HZ mortality incidence } \\
\text { per million person-years }\end{array}$ & & & & & & \multirow{6}{*}{$\begin{array}{l}\text { Statistics Netherlands [34]/incidence adjusted } \\
\text { for the immunocompetent population using } \\
\text { Hobbelen [49] }\end{array}$} \\
\hline 50-59 years & 0.1 & - & 0.3 & Beta & 0.1 & \\
\hline 60-69 years & 0.4 & 0.05 & 0.7 & Beta & 0.3 & \\
\hline 70-79 years & 1.8 & 0.9 & 2.8 & Beta & 1.6 & \\
\hline $80-89$ years & 16.5 & 12.6 & 20.5 & Beta & 14.3 & \\
\hline$\geq 90$ years & 108.9 & 84.6 & 133.2 & Beta & 94.5 & \\
\hline Misclassification $\mathrm{HZ}$ as & 47.5 & 32.0 & 63.0 & Beta & 0 & Mahamud [35]/assuming no misclassification \\
\hline
\end{tabular}

underlying cause of

death (\%)

QALY loss

QALY loss per HZ episode

$\begin{array}{lllll}50-59 \text { years } & 0.040 & 0.025 & 0.063 & { }^{a} \\ \geq 60 \text { years } & 0.057 & 0.039 & 0.093 & \end{array}$

Van Wijck [6]/utilities Van Hoek/QALY 
Table 1 Model inputs of the analysis. In the probabilistic sensitivity analysis, the parameter inputs were simultaneously varied within the lower and upper estimates according to the distribution shown. In the deterministic sensitivity analysis, the parameter inputs were varied one-by-one between lower and upper inputs, while the "scenario" column shows inputs based on other plausible assumptions or sources (Continued)

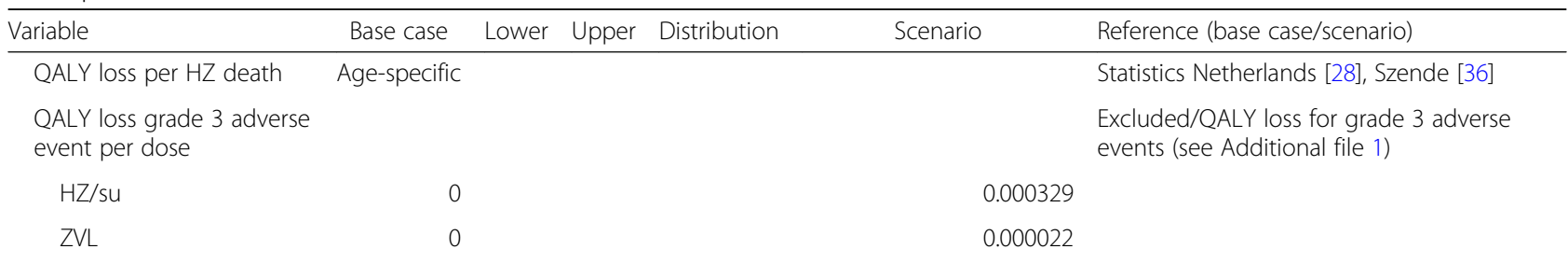

Costs $(€, 2017)$

Health care costs

GP visit, medication,

Based on multiple sources (see Additional file 1) specialist visit

\begin{tabular}{|c|c|c|c|}
\hline 50-59 years & 158 & 130 & 186 \\
\hline$\geq 60$ years & 198 & 163 & 233 \\
\hline \multicolumn{4}{|c|}{ ospital admission } \\
\hline 50-59 years & 2856 & 2490 & 3222 \\
\hline 60-69 years & 3632 & 3166 & 4097 \\
\hline 70-79years & 3671 & 3325 & 4016 \\
\hline$\geq 80$ years & 4504 & 4093 & 4915 \\
\hline
\end{tabular}

admission

Healthcare costs in gained life years per averted $\mathrm{HZ}$ death

Vaccine administration

Patient costs

OTC medication per

$\mathrm{HZ}$ episode

$$
\begin{aligned}
& 50-59 \text { years } \\
& \geq 60 \text { years }
\end{aligned}
$$$$
10.42
$$

Travel costs GP visit, medication, specialist care per $\mathrm{HZ}$ episode

$$
\begin{aligned}
& 50-59 \text { years } \\
& \geq 60 \text { years }
\end{aligned}
$$

hospitalization

Travel costs per vaccination

Productivity losses

HZ episode

$$
\begin{aligned}
& \text { 50-59 years } \\
& \text { 60-69 years }
\end{aligned}
$$

$\geq 70$ years

$\mathrm{HZ}$ death

$$
\begin{aligned}
& 50-59 \text { years } \\
& 60-69 \text { years } \\
& \geq 70 \text { years }
\end{aligned}
$$$$
14,937
$$$$
5074
$$ 
Table 1 Model inputs of the analysis. In the probabilistic sensitivity analysis, the parameter inputs were simultaneously varied within the lower and upper estimates according to the distribution shown. In the deterministic sensitivity analysis, the parameter inputs were varied one-by-one between lower and upper inputs, while the "scenario" column shows inputs based on other plausible assumptions or sources (Continued)

\begin{tabular}{|c|c|c|c|c|c|c|}
\hline Variable & Base case & Lower & Upper & Distribution & Scenario & Reference (base case/scenario) \\
\hline \multicolumn{7}{|l|}{ Vaccine characteristics } \\
\hline Vaccine uptake (\%) & 50 & & & & & Assumption based on Eilers [42] \\
\hline $\begin{array}{l}\text { Adherence to the second } \\
\text { dose of } \mathrm{HZ} / \mathrm{su}(\%)\end{array}$ & 100 & & & & $90,70,50$ & Assumption \\
\hline $\begin{array}{l}\text { Efficacy } \mathrm{HZ} / \mathrm{su} \text { over time } \\
\text { (linear function) }\end{array}$ & & & & & & $\begin{array}{l}\text { Function fitted using data from Cunningham } \\
\text { [20], Lal [19] and Curran [47] }\end{array}$ \\
\hline \multicolumn{7}{|l|}{ Intercept } \\
\hline 50-69 years & 0.981 & 0.904 & $1.057^{c}$ & Normal & & \\
\hline$\geq 70$ years & 0.992 & 0.956 & $1.028^{c}$ & Normal & & \\
\hline Slope ${ }^{b}$ & -0.041 & 0.018 & 0.065 & Beta & & \\
\hline $\begin{array}{l}\text { Efficacy ZVL over time } \\
\text { (one-minus-exponential }_{\text {function) }^{d}}\end{array}$ & & & & & $\begin{array}{l}\text { Additional efficacy against } \\
\mathrm{PHN} / \text { post-licensure } \\
\text { effectiveness against HZ }\end{array}$ & $\begin{array}{l}\text { Function fitted using data from Oxman [11], } \\
\text { Schmader [46] and Morrison [12]/see } \\
\text { Additional file } 1\end{array}$ \\
\hline Intercept & -0.893 & -1.04 & -0.75 & Normal & & \\
\hline Slope & 0.0807 & 0.058 & 0.104 & Beta & & \\
\hline $\begin{array}{l}\text { Risk ratio of efficacy } \\
\text { by age }\end{array}$ & & & & & & $\begin{array}{l}\text { Estimated using Rohan [45] and Schmader } \\
\text { [44]/see Additional file } 1\end{array}$ \\
\hline $50-59$ years & 1.282 & & & & & \\
\hline $60-64$ years & 1.274 & & & & & \\
\hline $65-69$ years & 1.219 & & & & & \\
\hline 70-74 years & 0.852 & & & & & \\
\hline $75-79$ years & 0.711 & & & & & \\
\hline $80-84$ years & 0.391 & & & & & \\
\hline$\geq 85$ years & 0.152 & & & & & \\
\hline
\end{tabular}

HZ herpes zoster, HZ/su HZ subunit vaccine, PHN post-herpetic neuralgia, QALY quality-adjusted life year, SNPG Stichting Nationaal Programma Grieppreventie, ZVL zoster vaccine live

${ }^{a}$ Aggregated costs from multiple cost items which were varied individually in the probabilistic sensitivity analysis (see Additional file 1)

${ }^{b}$ The slope of 0.009 was only used for 50 - to 69 -year-olds over the first 4 years covered by the trial. After 4 years, the slope of $\geq 70$-year-olds was used

'The efficacy was rounded to 1 during the period that the efficacy function was above 1

${ }^{\mathrm{d}}$ The efficacy of ZVL over time (in years) was modelled using a one-minus-exponential function $1-\exp \left(\beta_{1}+\beta_{2} \times\right.$ years), in which $\beta_{1}$ is the intercept and $\beta_{2}$ the slope. Risk ratios by age were used to modify the intercept. For instance, the efficacy of $60-64$ years at time point zero was $1-\exp (1.274 \times-0.893+0 \times 0.0807)=$ $67.9 \%$. In our model, we used the VE of the age group $60-64$ for vaccination of 60 -year-olds, $70-74$ for 70 -year-olds, $80-84$ for 80 -year-olds and $\geq 85$ years for the booster for 90-year-olds

obtained from the literature [32, 38]. According to the most recent Dutch guideline on cost-effectiveness research, unrelated healthcare costs in gained life years (i.e. indirect medical costs) should be included in the base case analysis [39]. These costs were estimated using the life expectancy at the age of death multiplied with yearly age-specific healthcare costs obtained from a specifically developed costing tool [40]. More details on the estimated costs per $\mathrm{HZ}$ episode are shown in Additional file 1. For vaccine administration costs, we used the current Dutch influenza tariff of $€ 11.36$ per dose, assuming that $\mathrm{HZ}$ vaccination would be provided in a GP-based programme [41]. This tariff covers, next to vaccine administration costs, costs due to patient selection and invitation, record keeping, vaccine storage and waste destruction.

\section{Vaccine characteristics}

Vaccine-related inputs are shown in Table 1. Given that ZVL is contraindicated to immunocompromised individuals, we restricted vaccination in our analysis to the immunocompetent part of the population. A recent questionnaire among a random sample of Dutch older adults aged $\geq 50$ years indicated that the acceptance rate of vaccination against $\mathrm{HZ}$ was 58\% [42]. Considering that the proportion of the Dutch population that is immunocompromised ranges from $1.9 \%$ in 50 - to 64 -year-olds to $11.5 \%$ in $\geq 85$-year-olds [43], we 
conservatively set the vaccination coverage at $50 \%$ of the total cohort. However, as we used a static model, the coverage has no impact on the cost-effectiveness outcomes of vaccination and was only used to estimate the absolute impact of vaccination such as the number of $\mathrm{HZ}$ cases prevented. We assumed that all $\mathrm{HZ} / \mathrm{su}$ recipients received two doses of the vaccine within 2 months and that the coverage of the $\mathrm{ZVL}$ booster after 10 years was $50 \%$ of the cohort that was still alive at that age.

Vaccine efficacy of HZ/su and ZVL against HZ over time was modelled using data from published clinical trials (see also Additional file 1: Figure S7) [11, 19, 20, 44-46]. For both vaccines, a function of vaccine efficacy over the years was fitted to the annual efficacy data using the standard error as a weighting factor. We fitted multiple types of functions and used the functions that provided the best fit. For $\geq$ 70 -year-olds, a linear function for two doses of $\mathrm{HZ} / \mathrm{su}$ was fitted to the 4 years of trial data, resulting in a waning of $4.1 \%$ per year. We assumed that this waning rate would continue after 4 years and varied this assumption extensively in the sensitivity analysis. For 50- to 69-year-olds, a recent study estimated the waning rate at $0.9 \%$ per year using unpublished annual vaccine efficacy estimates [47]. However, no confidence intervals of these estimates were reported, and the fit of a linear function through the annual vaccine efficacy estimates was poor. Therefore, we conservatively assumed that this waning rate was only valid for the first 4 years covered by the trial and would be equal to the $\geq 70$ years age group after 4 years. For ZVL, a one-minus-exponential function was fitted using follow-up data of $\geq 60$-year-olds up to 11 years after vaccination [12]. To include the effect of age, we adjusted the vaccine efficacy at take using age-specific risk ratios of the clinical trial. For the ZVL booster, we assumed that the efficacy would be equal to the efficacy that an initial dose would have had at that age [26]. More details on the model fits are provided in Additional file 1.

\section{Effectiveness and cost-effectiveness}

The effectiveness of the different $\mathrm{HZ}$ vaccination strategies was expressed as the number needed to vaccinate (NNV) to prevent a HZ case. The cost-effectiveness was estimated by finding the threshold vaccine cost that equals an incremental cost-effectiveness ratio (ICER) of $€ 20,000$ per QALY gained [25]. However, as this cost-effectiveness threshold does not have an official status in the Netherlands, we also show results for a threshold of $€ 50,000$ per QALY gained. The latter threshold has been used earlier for pneumococcal vaccination and is also considered by the Dutch National Health Care
Institute for therapeutic interventions of diseases with a moderate disease burden that could well be comparable to PHN $[25,48]$.

\section{Sensitivity analysis}

We performed a probabilistic sensitivity analysis (PSA) using 10,000 Monte Carlo simulations in which model inputs were simultaneously varied within their lower and upper ranges using specified distributions as shown in Table 1. Lower and upper ranges were estimated using the $95 \%$ CIs of the original sources. The PSA allowed us to estimate $95 \%$ credibility intervals $(95 \% \mathrm{CrI})$ of the burden of $\mathrm{HZ}$ using the 2.5 and 97.5 percentiles of the simulations. Additionally, the simulations of the PSA served as an input for a two-way sensitivity analysis, in which the vaccine cost per series of $\mathrm{HZ} / \mathrm{su}$ and per dose of ZVL were varied at the same time. For each individual simulation, the total costs and QALYs per alternative were converted to net monetary benefits (NMBs) using a cost-effectiveness threshold of $€ 20,000$ per QALY gained. Subsequently, for each combination of cost per series or dose, we analysed which alternative had the most simulations with the highest $\mathrm{NMB}$ and whether this proportion of simulations for the preferred alternative was above $90 \%$ or not.

Additionally, multiple deterministic sensitivity analyses were performed. The annual waning rate of $\mathrm{HZ} / \mathrm{su}$ after 4 years was varied between 0 and $10 \%$ using a time horizon of 15 years and a lifetime time horizon. We also did a one-way sensitivity analysis in which model inputs were varied one-by-one between their lower and upper ranges while keeping other values at their base case levels. Finally, several scenario analyses were performed to explore the impact of different methodological assumptions or inputs from other plausible sources (see scenario column in Table 1 and Additional file 1 for more details). These analyses included the use of epidemiological input estimates from an immunocompetent population; a lower adherence to the second dose of $\mathrm{HZ} / \mathrm{su}$ of $90 \%, 70 \%$ and $50 \%$ relative to the initial dose; and the attribution of a QALY penalty for vaccine-related grade 3 adverse events [4, 11, 19, 20, 49]. For ZVL, we additionally explored the impact of including additional efficacy against PHN as shown in the trial and the use of vaccine effectiveness data from various post-licensure studies $[11,14,16,50]$. For the latter, we selected three retrospective cohort studies based on the data from the US Kaiser Permanente Northern California database for the period 2007-2015, the US Medicare database for 2007-2014 and UK Clinical Practice Research Datalink database for 2013-2016, and for each study, we fitted a linear model (see Additional file 1 for details). 


\section{Reporting quality and model validation}

The reporting of the study adheres to the Consolidated Health Economic Evaluation Reporting Standards (CHEERS) checklist, and the model validation efforts are reported using the Assessment of the ValIdation Status of Health-Economic decision models (AdVISHE) questionnaire [51, 52]. Both checklists are added in Additional files 2 and 3.

\section{Results}

\section{Current burden of disease}

The estimated burden of HZ among the 2017 Dutch population aged $\geq 50$ years is presented in Table 2 . The total number of $\mathrm{HZ}$ cases is estimated at 54,169 (95\% CrI 52,130-56,174) per year, resulting in 434 hospital admissions, 805 1-day hospitalizations, 15 deaths and 3298 PHN cases. This generated a QALY loss of 2992 (95\% CrI 2418-3771). The major part of the health burden occurred among 60- to 79-year-olds, while most deaths were among $\geq 80$-year-olds. The total annual cost burden of $\mathrm{HZ}$ was estimated at $€ 19.6$ million (95\% CrI 16.3-22.6), including $€ 11.3$ million healthcare costs and $€ 7.7$ million non-healthcare costs. Most healthcare costs were due to GP visits, while non-healthcare costs predominantly consisted of productivity losses among 50to 69-year-olds.

\section{Impact of vaccination}

The impact of HZ vaccination is presented in Table 3. For each vaccination age, two doses of $\mathrm{HZ} /$ su were estimated to prevent considerably more $\mathrm{HZ}$ cases as compared to ZVL single dose or ZVL with a booster after 10 years. Depending on age, vaccination with $\mathrm{HZ} / \mathrm{su}$ at a coverage of $50 \%$ would avert 4335-10,896 HZ cases (34.6-37.9\% reduction) over the next 15 years, preventing 318-799 PHN cases, 257-600 lost QALYs and $€ 0.93-2.40$ million on costs to the society. Vaccination with ZVL would avert 400-4877 HZ cases (3.5-18.0\% reduction) and ZVL with a booster 427-6446 HZ cases (3.7-27.5\% reduction). In absolute terms, the highest number of cases would be prevented by vaccination of 70 -year-olds for $\mathrm{HZ} / \mathrm{su}$, while this was 60 -year-olds for ZVL and 50-year-olds for ZVL with a booster. As the model is static, the number of prevented $\mathrm{HZ}$ cases increases linearly with the coverage rate (Additional file 1: Figure S12). This figure shows that, for instance for

Table 2 Estimated annual burden of herpes zoster in the Netherlands among $\geq 50$-year-olds using January 2017 population data. The 95\%-credibility intervals were based on a probabilistic sensitivity analysis using 10,000 Monte-Carlo simulations

\begin{tabular}{|c|c|c|c|c|c|c|c|c|}
\hline & \multicolumn{5}{|l|}{ Age group } & \multirow[t]{2}{*}{ Total } & \multirow[t]{2}{*}{$95 \% \mathrm{Crl}-$} & \multirow[t]{2}{*}{$95 \% \mathrm{Crl}+$} \\
\hline & 50-59years & 60-69 years & 70-79years & $80-89$ years & $\geq 90$ years & & & \\
\hline Population & $2,473,222$ & $2,083,983$ & $1,379,744$ & 641,923 & 121,068 & $6,699,940$ & & \\
\hline \multicolumn{9}{|l|}{ Health outcomes } \\
\hline $\mathrm{HZ}$ cases & 13,160 & 16,065 & 14,772 & 8557 & 1614 & 54,169 & 52,130 & 56,174 \\
\hline Hospitalizations & 61 & 101 & 131 & 118 & 22 & 434 & 382 & 489 \\
\hline 1-day hospital admissions & 88 & 201 & 301 & 181 & 34 & 805 & 734 & 879 \\
\hline $\mathrm{HZ}$ deaths & 0 & 0 & 1 & 6 & 7 & 15 & 9 & 21 \\
\hline PHN cases & 289 & 1179 & 1084 & 628 & 118 & 3298 & 2474 & 4118 \\
\hline LYs lost & 4 & 7 & 16 & 39 & 27 & 93 & 56 & 144 \\
\hline QALYs lost & 531 & 941 & 873 & 530 & 116 & 2992 & 2418 & 3771 \\
\hline \multicolumn{9}{|l|}{ Costs (€, millions) } \\
\hline Healthcare costs & 2.27 & 3.50 & 3.37 & 1.91 & 0.23 & 11.28 & 9.57 & 13.43 \\
\hline GP visits, medication, specialist visits & 2.08 & 3.12 & 2.93 & 1.70 & 0.32 & 10.14 & 8.49 & 12.25 \\
\hline Hospitalizations & 0.18 & 0.37 & 0.48 & 0.53 & 0.10 & 1.66 & 1.41 & 1.93 \\
\hline 1-day hospital admissions & 0.02 & 0.06 & 0.08 & 0.05 & 0.01 & 0.23 & 0.21 & 0.25 \\
\hline Averted costs due to $\mathrm{HZ}$ preterm mortality ${ }^{\mathrm{a}}$ & -0.02 & -0.04 & -0.12 & -0.37 & -0.20 & -0.75 & -1.12 & -0.46 \\
\hline Non-healthcare costs & 5.02 & 2.28 & 0.25 & 0.14 & 0.03 & 7.73 & 5.85 & 9.83 \\
\hline Travel costs & 0.14 & 0.20 & 0.19 & 0.11 & 0.02 & 0.66 & 0.54 & 0.80 \\
\hline OTC medication & 0.04 & 0.07 & 0.06 & 0.04 & 0.01 & 0.22 & 0.18 & 0.26 \\
\hline Productivity loss & 4.84 & 2.01 & - & - & - & 7.44 & 4.99 & 11.81 \\
\hline Total costs & 7.29 & 5.78 & 3.62 & 2.05 & 0.26 & 19.59 & 16.33 & 24.62 \\
\hline
\end{tabular}

Crl credibility interval, GP general practitioner, $H Z$ herpes zoster, $L Y$ life year, OTC over-the-counter, $P H N$ post-herpetic neuralgia, $Q A L Y$ quality-adjusted life year ${ }^{a}$ Averted healthcare costs due to $\mathrm{HZ}$-related preterm mortality were estimated using the life expectancy and annual treatment costs per year from a standardized tool [40] 
Table 3 Impact, effectiveness and cost-effectiveness of vaccination of Dutch immunocompetent older adults against $\mathrm{HZ}$ at a coverage of 50\% over a period of 15 years. Vaccination strategies include the herpes zoster subunit vaccine (two doses) or zoster vaccine live (single dose, or single dose + booster after 10 years). Future costs and quality-adjusted life years (QALYs) include an annual discount rate of $4 \%$ and $1.5 \%$, respectively

\begin{tabular}{|c|c|c|c|c|c|c|c|c|}
\hline Vaccination strategy & $\begin{array}{l}\text { Total } \\
\mathrm{HZ} \text { cases }\end{array}$ & $\begin{array}{l}\mathrm{HZ} \text { cases } \\
\text { averted }\end{array}$ & $\begin{array}{l}\text { PHN cases } \\
\text { averted }\end{array}$ & $\begin{array}{l}\text { QALYS } \\
\text { gained }\end{array}$ & $\begin{array}{l}\text { Total costs } \\
\text { saved ( } € \text {, millions) }\end{array}$ & $\begin{array}{l}\text { NNV to } \\
\text { prevent a } \\
\text { HZ case }\end{array}$ & $\begin{array}{l}\text { Threshold vaccine } \\
\text { cost to equal } \\
€ 20,000 \text { per } \\
\text { QALY }(€)^{\mathrm{a}}\end{array}$ & $\begin{array}{l}\text { Threshold vaccine } \\
\text { cost to equal } \\
€ 50,000 \text { per } \\
\text { QALY }(€)^{\mathrm{a}}\end{array}$ \\
\hline \multicolumn{9}{|l|}{50 years } \\
\hline No vaccination & 22,613 & & & & & & & \\
\hline ZVL & 18,618 & 3995 & 118 & 159.3 & 2.060 & 31.7 & 29.59 & 67.29 \\
\hline ZVL + booster & 16,392 & 6220 & 281 & 268.1 & 2.777 & 20.4 & 27.09 & 65.51 \\
\hline $\mathrm{HZ} / \mathrm{su}$ & 14,141 & 8472 & 324 & 351.6 & 4.026 & 15.0 & 63.68 & 146.91 \\
\hline \multicolumn{9}{|l|}{60 years } \\
\hline No vaccination & 27,093 & & & & & & & \\
\hline ZVL & 22,215 & 4877 & 358 & 266.9 & 1.698 & 22.8 & 51.37 & 123.23 \\
\hline ZVL + booster & 20,627 & 6466 & 474 & 345.5 & 2.012 & 17.2 & 37.79 & 95.37 \\
\hline $\mathrm{HZ} / \mathrm{su}$ & 16,833 & 10,260 & 753 & 548.9 & 3.270 & 10.9 & 104.30 & 252.09 \\
\hline \multicolumn{9}{|l|}{70 years } \\
\hline No vaccination & 31,481 & & & & & & & \\
\hline ZVL & 28,368 & 3113 & 228 & 176.9 & 0.724 & 34.9 & 27.48 & 76.38 \\
\hline ZVL + booster & 27,645 & 3836 & 281 & 215.4 & 0.865 & 28.3 & 19.43 & 58.42 \\
\hline $\mathrm{HZ} / \mathrm{su}$ & 20,585 & 10,896 & 799 & 599.9 & 2.400 & 10.0 & 109.09 & 274.91 \\
\hline \multicolumn{9}{|l|}{80 years } \\
\hline No vaccination & 11,449 & & & & & & & \\
\hline $\mathrm{ZVL}$ & 11,050 & 400 & 29 & 24.7 & 0.092 & 117.0 & 0.73 & 16.56 \\
\hline ZVL + booster & 11,022 & 427 & 31 & 26.4 & 0.095 & 109.5 & -1.45 & 11.69 \\
\hline $\mathrm{HZ} / \mathrm{su}$ & 7114 & 4335 & 318 & 256.6 & 0.930 & 10.8 & 106.03 & 270.59 \\
\hline
\end{tabular}

$H Z$ herpes zoster, $H Z / s u$ herpes zoster subunit vaccine, NNV number needed to vaccinate, $P H N$ post-herpetic neuralgia, $Q A L Y$ quality-adjusted life-year, ZVL zoster vaccine live (live-attenuated vaccine)

${ }^{a}$ Cost per series (two doses) of HZ/su or cost per dose of ZVL. Administration costs of $€ 11.36$ per dose and travel costs of $€ 0.43$ per dose are not included

60-year-olds, vaccination with a series of $\mathrm{HZ} / \mathrm{su}$ at a coverage of $24 \%$ would avert an equal amount of $\mathrm{HZ}$ cases as vaccination with $\mathrm{ZVL}$ at a coverage of $50 \%$.

\section{Effectiveness and cost-effectiveness of vaccination}

Two doses of HZ/su was the most effective strategy for vaccination of 70 -year-olds ( $\mathrm{NNV}$ to prevent a $\mathrm{HZ}$ case of 10.0); however, there was little difference as compared to 60- and 80-year-old cohorts (NNVs of 10.9 and 10.8) (Table 3). For ZVL, vaccination age had a considerable impact on the effectiveness against HZ. The most effective age of vaccination was 60 years (NNV of 22.8), but the effectiveness decreased in the older cohorts (NNV of 34.9 for 70 years and 117.0 for 80 years). The effectiveness of ZVL would improve by adding a booster after 10 years, decreasing the NNV to 17.2 for vaccination of 60-year-olds, 28.3 for 70-year-olds and 109.5 for 80-year-olds.

The cost-effectiveness showed a similar pattern as compared to the effectiveness outcomes. For HZ/su, the maximum vaccine cost per series to remain cost-effective to a threshold of $€ 20,000$ per QALY gained was highest for vaccination of 70-year-olds, indicating that this would be the optimum age of vaccination from a cost-effectiveness point of view. The threshold vaccine cost per series at this age was estimated at $€ 109.09$. For $\mathrm{ZVL}$, the highest threshold vaccine cost per dose was $€ 51.37$ for vaccination of 60 -year-olds, while adding a booster dose after 10 years resulted in a decrease of the threshold cost per dose to $€ 37.79$. Our finding that a ZVL plus a booster had a lower threshold cost per dose as compared to ZVL single dose was also valid for shorter periods between the booster and the first dose, like 5 years. For the vaccination of 80 -year-olds, the threshold vaccine cost per dose of ZVL reached slightly above $€ 0$. The use of a higher cost-effectiveness threshold of $€ 50,000$ per QALY gained increased the maximum vaccine cost allowed considerably. Under this condition, the threshold cost per series of $\mathrm{HZ} / \mathrm{su}$ for vaccination of 70-year-olds increased to $€ 274.91$. 


\section{Sensitivity analyses}

A probabilistic two-way sensitivity analysis of the vaccine cost per dose of ZVL versus cost per series of $\mathrm{HZ} /$ $\mathrm{su}$ is shown in Fig. 1. For each vaccination age, there were combinations of vaccine cost in which either $\mathrm{HZ} /$ su, ZVL or ZVL with a booster was the most cost-effective alternative. The competition between $\mathrm{HZ} / \mathrm{su}$ and ZVL was the highest for 60 -year-olds. For instance, if the cost per series of $\mathrm{HZ} / \mathrm{su}$ was assumed at $€ 100$, the maximum cost per dose of ZVL to be the most cost-effective alternative was estimated $€ 46.75$. A ZVL booster after 10 years had a higher probability of being cost-effective among 50-year-olds than ZVL single dose when the cost per dose of ZVL was below $€ 21.25$. With regard to uncertainty, $\mathrm{HZ} / \mathrm{su}$ had a more than $90 \%$ probability of being the most cost-effective alternative as

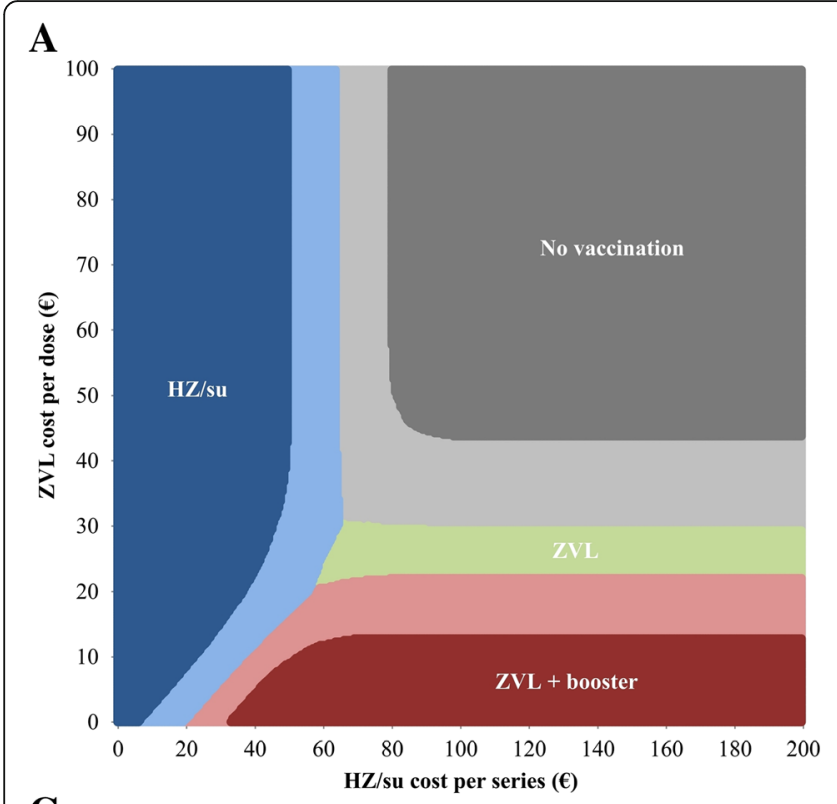

\section{B}

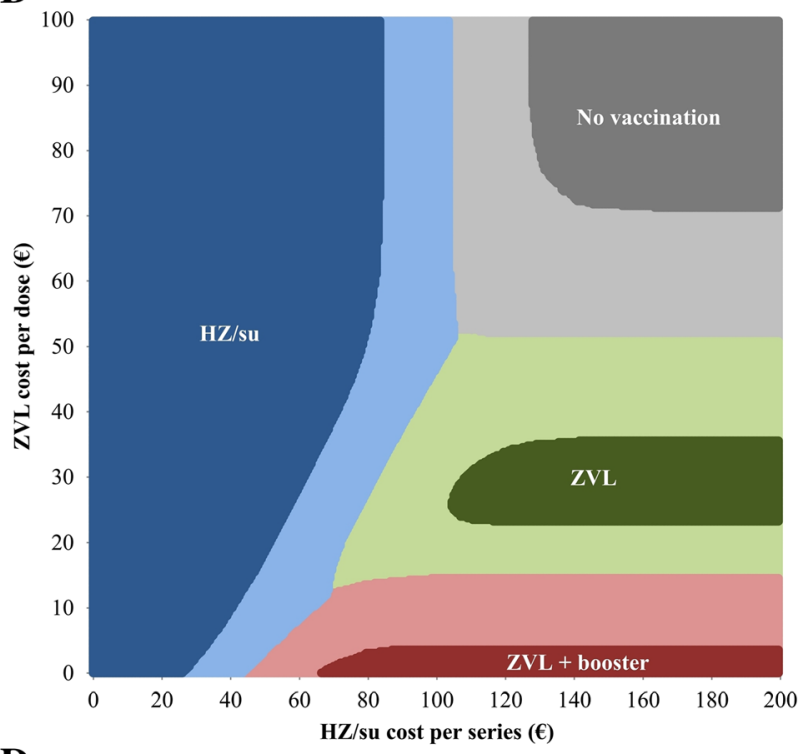

C

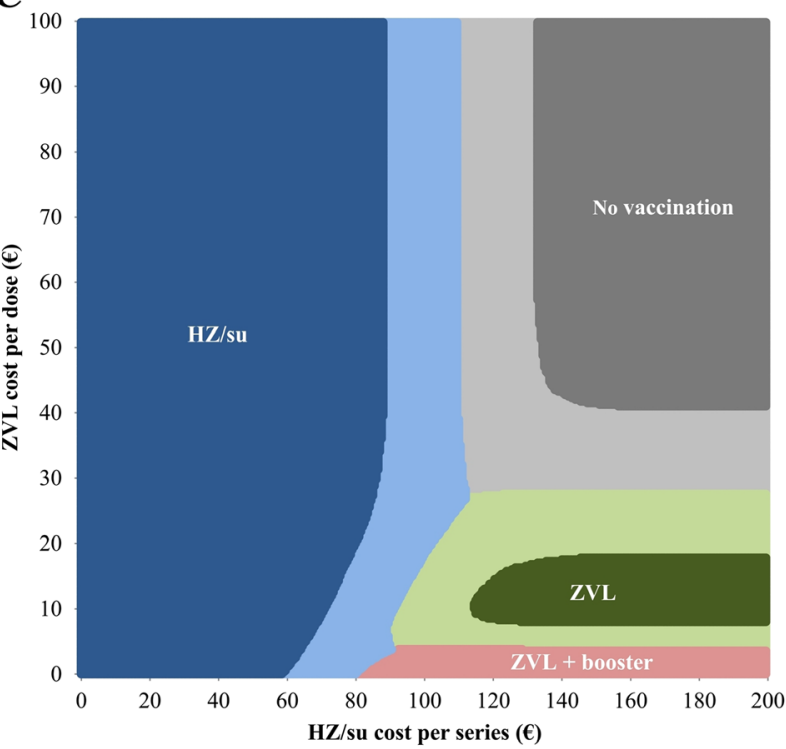

D

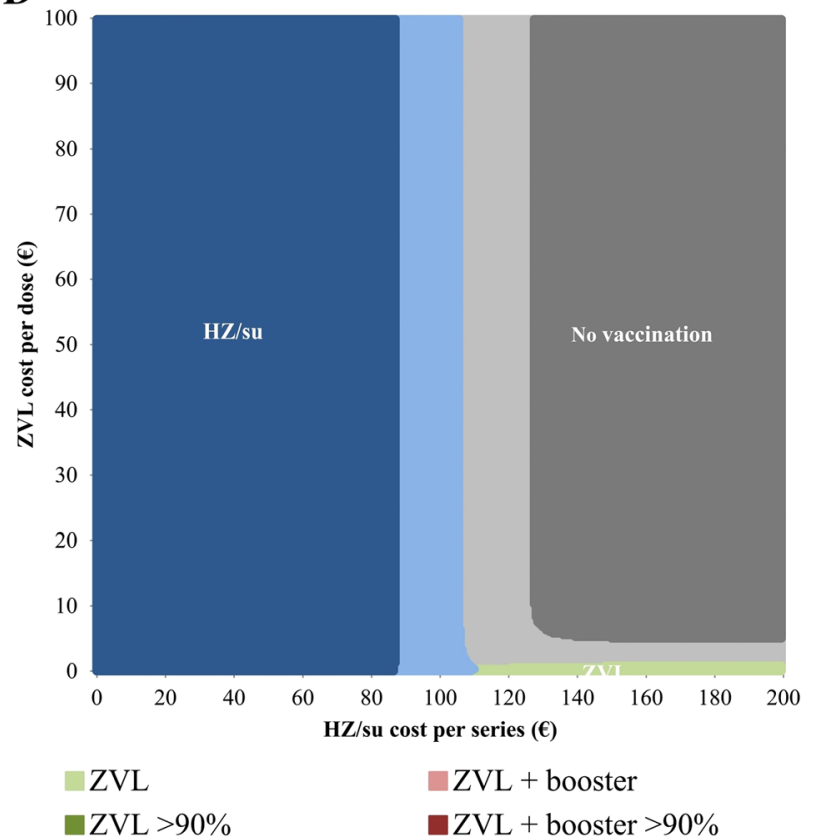

No vaccination

$\mathrm{HZ} / \mathrm{su}$

No vaccination $>90 \%$

$\mathrm{HZ} / \mathrm{su}>90 \%$

ZVL $>90 \%$

$\mathrm{ZVL}+$ booster $>90 \%$

Fig. 1 Two-way sensitivity analysis of the vaccine cost per series of $\mathrm{HZ} / \mathrm{su}$ and vaccine cost per dose of ZVL for vaccination of a 50-year-olds, $\mathbf{b}$ 60-year-olds, c 70-year-olds and d 80-year-olds. After performing a probabilistic sensitivity analysis using 10,000 Monte Carlo simulations, the alternative with the highest probability of being cost-effective to a willingness-to-pay threshold of $€ 20,000$ per QALY gained is presented over a range of vaccine cost. Dark coloured areas indicate that the probability of being the most cost-effective alternative is higher than $90 \%$. $\mathrm{HZ} / \mathrm{su}$, herpes zoster subunit vaccine; QALY, quality-adjusted life year; ZVL, zoster vaccine live 
compared to no vaccination when the vaccine cost per series would fall below $€ 49.74$, $€ 85.80, € 83.64$ and $€ 87.56$ for 50-, 60-, 70- and 80-year-olds, respectively.

Figure 2 shows the impact of the annual waning rate of $\mathrm{HZ} / \mathrm{su}$ starting 4 years following vaccination, both when using a time horizon of 15 years (Fig. 2a, base case) and when using a lifetime time horizon (Fig. 2b, sensitivity analysis). Over a period of 15 years, the threshold vaccine cost per series for vaccination of 70 -year-olds with $\mathrm{HZ} / \mathrm{su}$ would change to $€ 140.44$ in the absence of waning and to $€ 69.18$ when a waning rate of $10 \%$ per year was assumed. With regard to the
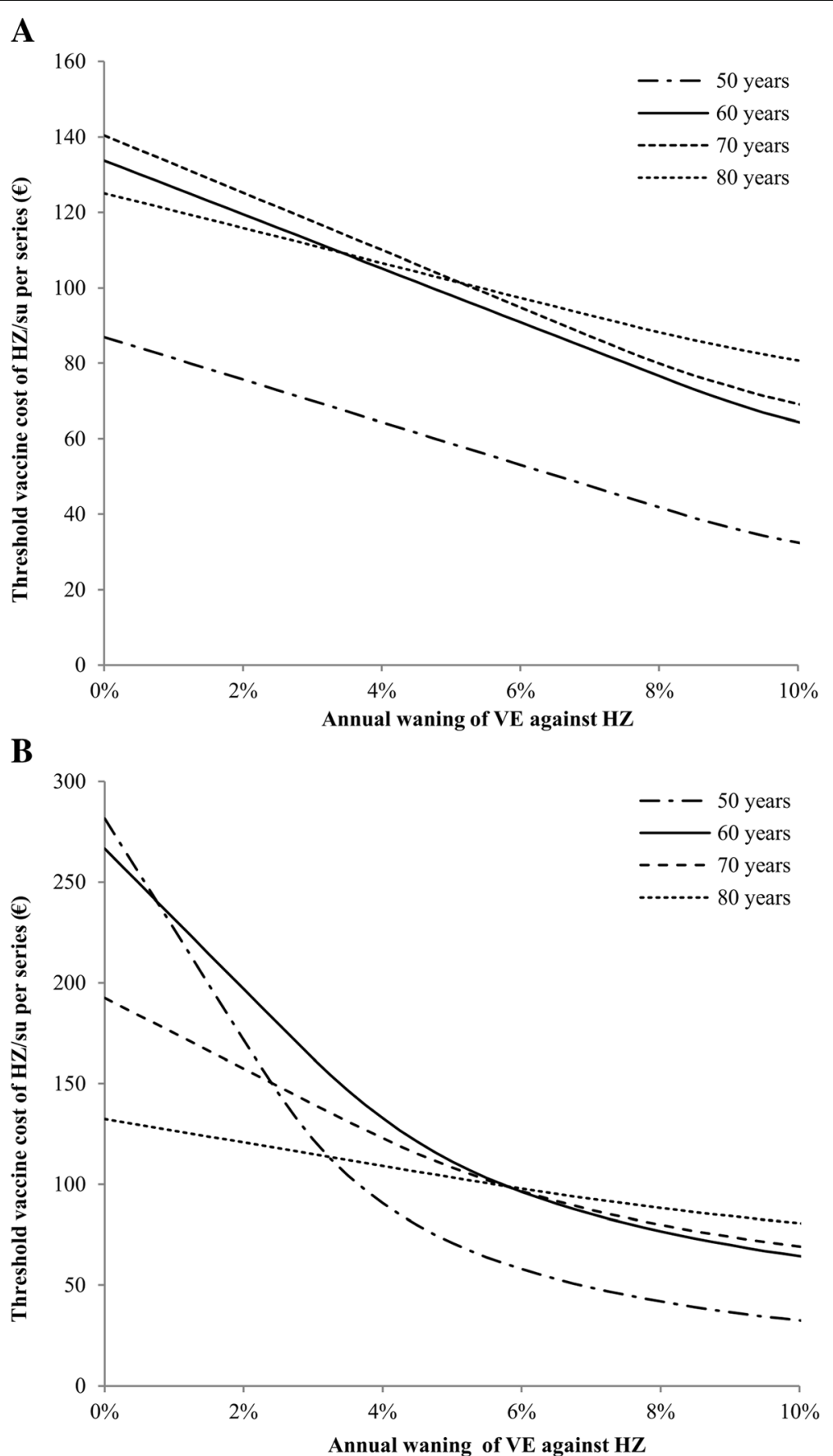

Fig. 2 Impact of the annual $\mathrm{HZ} / \mathrm{su}$ waning rate starting 4 years following vaccination on the threshold vaccine cost per series when using a a time horizon of 15 years or $\mathbf{b}$ a lifetime time horizon. The cost-effectiveness threshold was set at $€ 20,000$ per quality-adjusted life year gained. $\mathrm{HZ}$, herpes zoster; $\mathrm{HZ} / \mathrm{su}$, herpes zoster subunit vaccine; VE, vaccine efficacy 
optimum vaccination age, 80 years would become the most cost-effective alternative when the waning rate was higher than $5.0 \%$ per year. Using a lifetime time horizon, the threshold cost per series of $\mathrm{HZ} / \mathrm{su}$ increased to $€ 120.94$ for vaccination of 70 -year-olds at a waning rate of $4.1 \%$ per year as used in the base case analysis. Furthermore, vaccination of 50- and 60-yearolds would become more cost-effective as compared to 70 - and 80 -year-olds when the waning rate would be lower than $2.3 \%$ per year. A sensitivity analysis on the time horizon shows that after 5 years, the threshold vaccine cost was $€ 40.39$ per series of $\mathrm{HZ} / \mathrm{su}$ and $€ 18.88$ per dose of ZVL for vaccination of 70 -year-olds
(Additional file 1: Figure S13). Figure 3 shows a deterministic sensitivity analysis and a scenario analysis for $\mathrm{HZ} / \mathrm{su}$ at vaccination age of 70 years. The deterministic sensitivity analysis shows that the uncertainty around the waning rate and parameters involved in the estimation of the QALY loss per HZ episode (probability of $\mathrm{HZ}$ pain, waning of long-term $\mathrm{HZ}$ pain and $\mathrm{HZ}$ utilities) had the highest impact on the cost-effectiveness (Fig. 3a). The scenario analysis demonstrates that the threshold vaccine cost per series of $\mathrm{HZ} / \mathrm{su}$ decreased to $€ 80.54$ when $\mathrm{HZ}$ incidence estimates from an immunocompetent population were used (Fig. 3b). Reduction of the adherence to the second dose of $\mathrm{HZ} / \mathrm{su}$

A

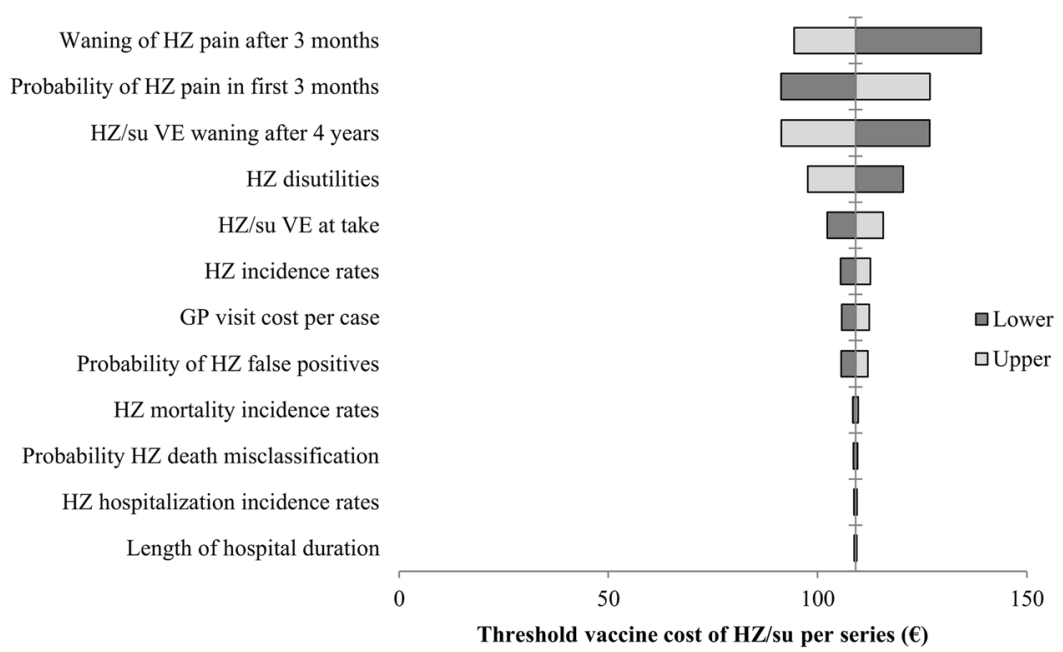

B

QALY loss per HZ case by Van Hoek et al. No HZ false positives

No discounting

No $\mathrm{HZ}$ death misclassification

Excluding $\mathrm{HC}$ costs in gained LY

Discount rate: Costs 1.5\% / QALYs 1.5\%

Utility weights by Van Hoek et al.

Excluding non-health care costs (HCP perspective)

$90 \%$ adherence to second dose

$70 \%$ adherence to second dose

Discount rate: Costs 3\% / QALYs 3\%

QALY penalty side effects

$50 \%$ adherence to second dose

Incidence rates immunocompetent population

Threshold vaccine cost of $\mathrm{HZ} /$ su per series $(€)$

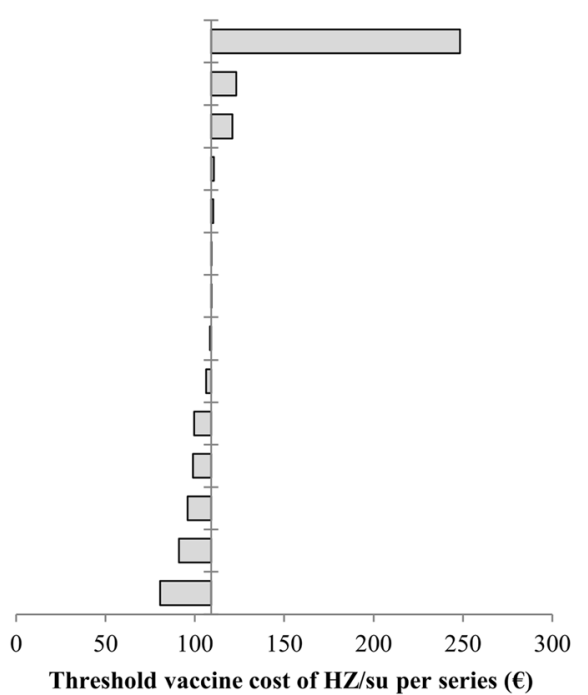

Fig. 3 One-way sensitivity analysis of $\mathrm{HZ} / \mathrm{su}$ for vaccination of 70-year-olds. The threshold vaccine cost per series is the maximum cost to remain below a threshold of $€ 20,000$ per QALY gained. a Deterministic sensitivity analysis showing the impact of parameter uncertainty by using the lower (dark grey) and upper (light grey) ranges that were based on the $95 \%$ confidence intervals of the input parameters. b Scenario analysis showing the impact of structural uncertainty by using other plausible model inputs. GP, general practitioner; $\mathrm{HC}$, healthcare; $\mathrm{HCP}$, healthcare payer; HZ, herpes zoster; HZ/su, herpes zoster subunit vaccine; PHN, post-herpetic neuralgia; QALY, quality-adjusted life year; VE, vaccine efficacy 
to $90 \%, 70 \%$ and $50 \%$ resulted in lower threshold vaccine cost per series of $€ 106.24$, $€ 99.54$ and $€ 91.05$, respectively. The inclusion of a QALY loss due to grade 3 adverse events decreased the threshold vaccine cost per series to $€ 95.93$. The highest impact on the costeffectiveness was found for using QALY loss estimates per $\mathrm{HZ}$ case as previously estimated by Van Hoek et al. [31]. In this scenario, the threshold vaccine cost per series of $\mathrm{HZ} / \mathrm{su}$ increased to $€ 248.38$. Other scenarios that altered the threshold vaccine cost by more than $10 \%$ included the use of equal discount rates of $4 \%$ for costs and effects, no discounting and the exclusion of $\mathrm{HZ}$ false positives. Deterministic sensitivity analyses from other age cohorts showed similar results, except that the exclusion of non-healthcare costs resulted in a more than $10 \%$ decrease of the threshold vaccine cost per series among 50-year-olds.

Additional scenarios for ZVL included the consideration of additional efficacy against PHN and the use of post-licensure effectiveness data (Fig. 4). The inclusion of additional efficacy against PHN increased the threshold vaccine cost for 70 - and 80-year-olds to $€ 34.56$ and $€ 6.52$, respectively. The use of ZVL effectiveness data resulted in a decrease of the threshold vaccine cost per dose for 60-year-olds but in a substantial increase for 80 -year-olds. For instance, on the basis of 8 years of data from the US Kaiser Permanente Southern California database, the threshold vaccine cost per dose of ZVL for 80-year-olds was estimated at $€ 23.64$.

\section{Discussion}

Our analysis demonstrates that vaccination with two doses of $\mathrm{HZ} / \mathrm{su}$ would result in a substantially higher number of $\mathrm{HZ}$ cases prevented and number of QALYs gained as compared to ZVL (single dose or single dose + booster). This was explained by the relatively higher efficacy of $\mathrm{HZ} / \mathrm{su}$. However, whether vaccination with $\mathrm{HZ} /$ su would be cost-effective as compared to no vaccination or to ZVL depends largely on the vaccine cost per series. We found that especially for the 60 -year-old cohort, there are pricing scenarios in which ZVL could potentially be the most cost-effective alternative. Adding a ZVL booster after 10 years was expected to reduce the effectiveness gap between $\mathrm{ZVL}$ and $\mathrm{HZ} /$ su but required a significant decrease of the vaccine cost per dose to be the most cost-effective alternative. The inclusion of additional efficacy against PHN or the use of recent post-licensure effectiveness data of ZVL was found to improve the cost-effectiveness of ZVL among $\geq$ 70-year-olds, increasing the competition between the two vaccines in these age cohorts.

\section{Implications and possible explanations for findings}

A threshold of $€ 20,000$ per QALY gained is the general Dutch cost-effectiveness threshold for healthcare interventions such as vaccination. At optimum vaccination age, i.e. 70 years for $\mathrm{HZ} / \mathrm{su}$ and 60 years for $\mathrm{ZVL}$, the maximum vaccine costs to remain cost-effective were estimated at $€ 109$ per series and $€ 51$ per dose, respectively.

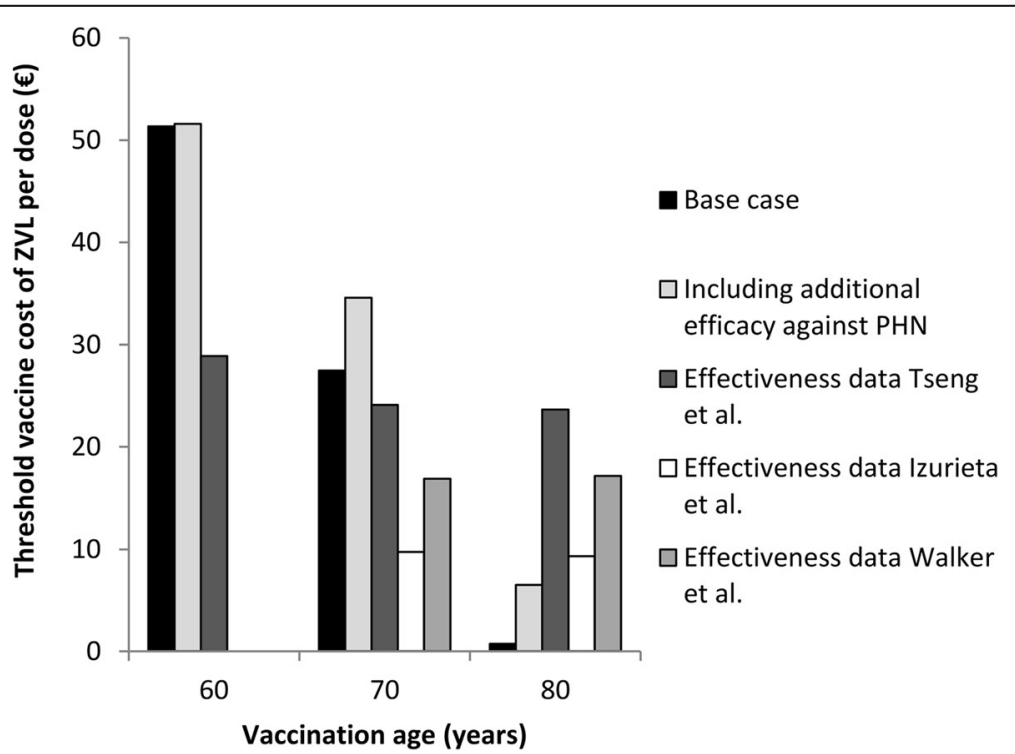

Fig. 4 Impact of the inclusion of additional efficacy against PHN using trial data and the use of effectiveness data against $\mathrm{HZ}$ on the threshold vaccine cost per dose of ZVL. The cost-effectiveness threshold was set at $€ 20,000$ per quality-adjusted life year gained. Effectiveness data from three data sources, i.e. the US Kaiser Permanente Southern California database [14], the US Medicare database [16] and the UK Clinical Practice Research Datalink database [50], were explored. For the Medicare and Clinical Practice Research Datalink database, no effectiveness data of 60year-olds was available. PHN, post-herpetic neuralgia; QALY, quality-adjusted life year; ZVL, zoster vaccine live 
These estimates are considerably lower than the currently available vaccine costs of $\mathrm{ZVL}$ and $\mathrm{HZ} / \mathrm{su}$ in the private sector. For instance, the private sector cost of two doses of $\mathrm{HZ} / \mathrm{su}$ would be $€ 226$ (US\$280) according to the price list of the Centers for Disease Control and Prevention, and the private sector cost per dose of ZVL in the Netherlands is currently $€ 145$ [53, 54]. Our model shows that $\mathrm{HZ}$ vaccination would not be cost-effective with either $\mathrm{HZ} / \mathrm{su}$ or $\mathrm{ZVL}$ when the above-mentioned vaccine costs are used.

The optimum age of vaccination with $\mathrm{HZ} / \mathrm{su}$ would be in the range of 60 to 80 years, as the efficacy is relatively constant with vaccination age. However, the cost-effectiveness and the optimum age of vaccination with $\mathrm{HZ} / \mathrm{su}$ were highly sensitive to the duration of protection. Currently, the waning rate had to be estimated using 4 years of follow-up data from the trial, showing a decrease in efficacy over time. However, a closer look to the trial data by arm shows that the waning of efficacy within the first 4 years may be caused by a decrease of $\mathrm{HZ}$ incidence in the placebo group rather than an increase of $\mathrm{HZ}$ incidence in the vaccinated group [20]. Such a decrease of $\mathrm{HZ}$ incidence over time in the placebo group is unexpected because the risk of $\mathrm{HZ}$ usually increases with age. Our sensitivity analysis demonstrated that a lower waning rate would have a substantial impact on decision-making, as the optimum age of vaccination changed from 60 to 80 years to $50-60$ years when a lifetime time horizon was used.

Based on the trial data, the optimum vaccination age of ZVL was 60 years and decreased rapidly with increasing age. However, sensitivity analyses of ZVL demonstrated that the cost-effectiveness of ZVL improves substantially for $\geq 70$-year-olds when an additional efficacy against PHN was taken into account. Post-licensure studies also confirmed that ZVL was likely to provide additional protection against PHN as well as to other severe outcomes like ophthalmic HZ and HZ-related hospitalizations [14, $17,50,55]$. Moreover, effectiveness studies in the US and UK found a relatively stable effectiveness of ZVL with increasing age, explaining why in our sensitivity analysis the cost-effectiveness decreases for 60-year-olds but improves considerably for 80-year-olds when this data was explored in our model. This implies that based on trial data only, the impact of ZVL might be underestimated for the eldest and that ZVL could be a competitor for $\mathrm{HZ} / \mathrm{su}$ across all age groups. However, it should be noted that although effectiveness studies are more representative for real-life conditions and have more statistical power due to larger sample sizes, they can be affected by uncontrolled confounders. For instance, observational studies rely on the healthcare registries and are therefore more likely to include severe cases as compared to clinical trials that use active surveillance.
Next to cost-effectiveness, budget impact is often considered to be important to decision-makers. As most of the gains are due to the reduction of the burden of illness, vaccination would increase the total healthcare expenditure on HZ considerably. In budget impact analyses, usually a relative short time horizon of maximum 5 years is used and future costs and health effects are not discounted. Under these conditions, the average annual budget impact of vaccination of $50 \%$ of the 60-year-olds would be $€ 6.0$ million per year for ZVL (one-dose schedule) and $€ 12.7$ million per year for $\mathrm{HZ} /$ su (two-dose schedule), when corresponding maximum vaccine costs per series of $€ 51$ per dose for $Z V L$ and $€ 104$ for $\mathrm{HZ} / \mathrm{su}$ were used. This implies that the implementation of $\mathrm{HZ} / \mathrm{su}$ would result in a twofold increase of the total healthcare expenditure on $\mathrm{HZ}$ as compared to ZVL and a more than fourfold increase as compared to no vaccination.

As $\mathrm{HZ} / \mathrm{su}$ needs to be administered twice within 2-6 months, vaccination will result in higher healthcare utilization as compared to ZVL that is given as a single dose. Moreover, the prospect of a two-dose regimen might also result in a lower uptake as compared to a one-dose regimen. But we do also note that $\mathrm{HZ} / \mathrm{su}$ is registered for immunocompromised populations as well, which might be beneficial to the overall vaccination coverage. Both vaccines can be safely combined with influenza vaccination [56, 57], which might facilitate the implementation and save administration costs. However, influenza vaccination is only given once a year, and immunogenicity data indicates that revaccination with $\mathrm{HZ} / \mathrm{su}$ after 12 months is less immunogenic as compared to 2-6 months after the first dose [58]. Our sensitivity analysis shows that the adherence to the second dose of $\mathrm{HZ} / \mathrm{su}$ impacts the cost-effectiveness considerably, as a single dose of $\mathrm{HZ} / \mathrm{su}$ is expected to have a substantially lower efficacy, especially among $\geq 70$-year-olds, and a higher waning rate as compared to two doses [47].

Safety studies showed that both $\mathrm{HZ} / \mathrm{su}$ and ZVL were not associated with serious adverse events among immunocompetent older adults but that $\mathrm{HZ} / \mathrm{su}$ gives a substantially higher risk of grade 3 adverse events and local adverse events as compared to ZVL [59]. On the other hand, vaccination with $\mathrm{HZ} / \mathrm{su}$ can also reduce the risk of serious adverse events because post-licensure studies of ZVL indicate that immunocompromised individuals were, although its contraindication, occasionally vaccinated [15, 17]. ZVL can cause serious adverse events in immunocompromised patients, as it may result in a symptomatic, progressive infection of the vaccine virus, causing severe rashes [60].

During the evaluation of ZVL by the Dutch Health Council in 2016, it was concluded that vaccination 
against $\mathrm{HZ}$ did not meet the criteria to be included in the national immunization programme because it does not control VZV transmission nor does it prevent significant mortality [13]. Vaccination against HZ might however be indicated for a public programme when the vaccine would be regarded as essential healthcare due to a substantial reduction of the individual disease burden [61]. The Dutch Health Council considered ZVL not as essential healthcare because of its relatively low efficacy in the eldest, short duration of protection and the contraindication for immunocompromised individuals [13]. Our results demonstrate that $\mathrm{HZ} / \mathrm{su}$ is expected to have a significantly higher impact on the health economic burden of $\mathrm{HZ}$ as compared to ZVL (without or with a booster after 10 years), especially among $\geq 70$-year-olds.

In our opinion, these results are also of interest to other countries that are reconsidering $\mathrm{HZ}$ vaccination. Recently, the US Advisory Committee on Immunization Practices (ACIP) decided to (i) give HZ/su a preferential status above the ZVL vaccine, (ii) extend the target group from all immunocompetent $\geq 60$-year-olds to all immunocompetent $\geq 50$-year-olds and (iii) revaccinate individuals that had previously been vaccinated with ZVL [59]. The UK launched a publicly funded vaccination programme using ZVL for 70-year-olds with a catch-up for 78-year-olds in 2013 [62] but now needs to decide whether vaccination with $\mathrm{HZ} / \mathrm{su}$ should be preferred above ZVL, and if so, whether ZVL-vaccinated individuals should be revaccinated with $\mathrm{HZ} / \mathrm{su}$. Since the UK Joint Committee on Vaccination and Immunisation recently suggested a similar cost-effectiveness threshold for vaccines as compared with the Netherlands of $£ 15,000(€ 17,400)$ per QALY gained [63] and the incidence of HZ tends to be similar across European countries [64], the HZ/su threshold vaccine cost per series might be in the same range as we estimated for the Dutch setting. However, the cost-effectiveness of $\mathrm{HZ} / \mathrm{su}$ in a cohort that is vaccinated with ZVL will presumably be decreased due to a remaining protection offered by ZVL. For instance, with the use of our model, the threshold vaccine cost per series of $\mathrm{HZ} / \mathrm{su}$ among 70 year-olds decreased from $€ 109.2$ per dose to $€ 80.4$, $€ 97.6$ and $€ 107.2$ per series at 1,3 and 5 years, respectively, after vaccination with ZVL, when using published vaccine effectiveness data from the UK [50].

\section{Comparison with other studies}

A recent study from the US found that the cost-effectiveness of vaccination of 60-year-olds against $\mathrm{HZ}$ would remain below a cost-effectiveness threshold of US\$50,000 $(€ 40,400)$ per QALY gained when the vaccine cost per series was below US\$360 (€290) for HZ/su and US\$350 (€282) for ZVL [21]. These costs were, after adjusting for the higher cost-effectiveness threshold, relatively higher as compared to our findings, which can be explained by the use of a lifetime time horizon, a threefold higher healthcare costs per $\mathrm{HZ}$ episode and the inclusion of additional protection against PHN and burden of illness. With the same model, it was demonstrated that a HZ/su booster in individuals previously vaccinated with $Z V L$ would only be cost-effective within 5 years after vaccination if the adherence to the second dose of HZ/su approached 100\% [65]. A public health impact study for Germany estimated a similar NNV to prevent a HZ case among $\geq 70$-year-olds of 10 for $\mathrm{HZ} /$ su and somewhat higher NNV of 50 for ZVL [47]. A cost-effectiveness analysis with the same model found that the ICER of vaccination with $\mathrm{HZ} /$ su ranged between $€ 37,000$ and $€ 44,000$ per QALY gained when the cost per series was $€ 220$ [22]. A recent study from Italy estimated the cost-effectiveness of ZVL while taking into account the effect of demographic changes over time and an accompanying varicella vaccination programme [5]. They found that the incidence of $\mathrm{HZ}$ is expected to increase over the next decades due to the ageing of the population, that varicella vaccination might cause a further increase of the incidence of $\mathrm{HZ}$ because of the reduction of exogenous boosting and that $\mathrm{HZ}$ vaccination would cost-effectively reduce this increasing burden of HZ. Finally, two earlier Dutch studies assessing the cost-effectiveness of ZVL estimated ICERs of $€ 22,000$ per QALY gained and $€ 30,000$ per QALY gained for 70 -year-olds using vaccine cost per dose of $€ 77$ and $€ 87$, respectively [66, 67]. The most important explanation for finding a relatively lower threshold cost per dose in our current study was a substantially lower QALY loss per HZ case. Some other differences were the use of updated $\mathrm{HZ}$ incidence rates and long-term efficacy data of ZVL.

\section{Strengths and limitations}

The main strength of our study is that we were able to combine high-quality vaccine efficacy data from large clinical trials with $\mathrm{HZ}$ burden estimates from national data sources. HZ incidence was obtained from a GP network that has been validated as a good representation of the general Dutch population. Cost and QALY loss estimates were obtained from a large Dutch prospective cohort study with a long-term follow-up period of 12 months after onset and using the validated EQ-5D instrument to estimate HR-QoL. Moreover, we included a vaccination alternative of ZVL with a booster in our analysis, which has not been compared with $\mathrm{HZ} / \mathrm{su}$ so far and we are the first exploring post-licensure effectiveness data of ZVL in a cost-effectiveness model.

Our analysis also has its limitations. The duration of protection of $\mathrm{HZ} / \mathrm{su}$ is currently unknown, which 
appeared to be an important parameter in the sensitivity analysis. Next, data on adherence to the second dose of $\mathrm{HZ} / \mathrm{su}$ and the efficacy and waning of one dose of HZ/ su is scarce, which also was shown to have an impact on the cost-effectiveness. Also, applying data from the total Dutch population on immunocompetent cohorts might have led to an overestimation of the impact of vaccination. However, we performed a sensitivity analysis by adjusting the epidemiological parameters for this aspect. The patient recruitment and data acquisition of the prospective cohort study that was mainly used for the estimation of HZ-related costs and QALY losses were partly web-based, which might have introduced a selection bias due to the inclusion of healthier subjects able to understand and fill out a web-based questionnaire. However, the target group in our model consisted of immunocompetent individuals, which might also represent a healthier cohort than the general population. Finally, rare HZrelated complications like monaural deafness and monocular blindness were not included in our model.

\section{Future recommendations}

For the future, we recommend an update of our analysis when long-term efficacy data of $\mathrm{HZ} / \mathrm{su}$ become available. Currently, the long-term duration of protection of $\mathrm{HZ} /$ $\mathrm{su}$ is investigated in a subpopulation of the trial, while also the impact of revaccination with one or two doses of $\mathrm{HZ} / \mathrm{su}$ will be assessed [68]. Next, we would recommend cost-effectiveness studies specifically for immunocompromised populations. Recent non-peer-reviewed results of $\mathrm{HZ} / \mathrm{su}$ for autologous haematopoietic stem cell transplant recipients showed that $\mathrm{HZ} / \mathrm{su}$ was $68.2 \%$ (95\% CI 55.6-77.5) efficacious against HZ, while no safety issues occurred [69]. As the risk of HZ among autologous haematopoietic stem cell transplant recipients has been estimated at $16-31 \%$ within the first year after transplantation [70], vaccination of such a target group might potentially result in improved cost-effective outcomes as compared to vaccination of immunocompetent individuals only.

\section{Conclusions}

Two doses of HZ/su was found to be superior in reducing the burden of $\mathrm{HZ}$ among Dutch immunocompetent older adults as compared to ZVL single dose or ZVL single dose with a booster after 10 years. Vaccination could potentially be cost-effective for both $\mathrm{HZ} / \mathrm{su}$ and ZVL in the context of the conventional Dutch cost-effectiveness threshold of $€ 20,000$ per QALY gained, but this depends largely on the vaccine cost. It is anticipated that these results will be useful for policy-makers in the Netherlands and in all other countries considering $\mathrm{HZ}$ vaccination.

\section{Additional files}

Additional file 1: Supplemental methods. (DOCX $567 \mathrm{~kb}$ )

Additional file 2: CHEERS checklist. (DOCX $27 \mathrm{~kb}$ )

Additional file 3: AdVISHE checklist. (DOCX 42 kb)

\section{Abbreviations}

ACIP: Advisory Committee on Immunization Practices; AdVISHE: Assessment of the Valldation Status of Health-Economic decision models;

CHEERS: Consolidated Health Economic Evaluation Reporting Standards; Cl: Confidence interval; EQ-5D-3L: Euroqol-5 dimensions-3 level version; GP: General practitioner; HR-QoL: Health-related quality of life; HZ: Herpes zoster; HZ/su: Herpes zoster subunit vaccine; ICD: International Statistical Classification of Diseases and Related Health Problems; ICER: Incremental costeffectiveness ratio; LY: Life year; NMB: Net monetary benefit; NNV: Number needed to vaccinate; OTC: Over-the-counter; PHN: Post-herpetic neuralgia; PSA: Probabilistic sensitivity analysis; QALY: Quality-adjusted life year; UK: United Kingdom; US: United States; VZV: Varicella-Zoster virus; ZVL: Zoster vaccine live

\section{Acknowledgements}

We would like to thank Mathijs Fledderus for his help on the development of the model and Jan van de Kassteele for his suggestions on the model fit of the vaccine efficacy over time.

Funding

No external funding has been received for this study.

\section{Availability of data and materials}

All relevant data are within the paper. Further details are available from the first author on reasonable request.

\section{Authors' contributions}

PTdB (guarantor), AvL, HdM, AJvH and MJP conceptualized the study. PTdB developed the model, undertook the analysis and wrote the first draft of the paper. AvL and AJMvW prepared the input data and commented on the paper. HdM, JCW, AJvH and MJP commented on the paper. All authors read and approved the final manuscript.

\section{Ethics approval and consent to participate}

None required.

\section{Consent for publication}

None required.

\section{Competing interests}

No external funding has been received for this study. PTdB, AvL, HdM and AJvH report no conflict of interest. AJMvW has received a grant from Sanofi Pasteur MSD, which was unrelated to this project. JCW and MJP have received grants and honoraria from various pharmaceutical companies, including those developing, producing and marketing zoster vaccines, but all unrelated to this project.

\section{Publisher's Note}

Springer Nature remains neutral with regard to jurisdictional claims in published maps and institutional affiliations.

\section{Author details}

${ }^{1}$ Centre for Infectious Disease Control, National Institute for Public Health and the Environment, Antonie Van Leeuwenhoeklaan 9, 3721 MA Bilthoven, The Netherlands. ${ }^{2}$ Unit of PharmacoTherapy, -Epidemiology \& -Economics (PTE2), University of Groningen, Groningen Research Institute of Pharmacy, Groningen, The Netherlands. ${ }^{3}$ Pain Clinic, University Medical Centre Utrecht, Utrecht, The Netherlands. ${ }^{4}$ Department of Medical Microbiology, University Medical Center Groningen, University of Groningen, Groningen, The Netherlands. ${ }^{5}$ Department of Infectious Disease Epidemiology, Faculty of Epidemiology and Population Health, London School of Hygiene \& Tropical Medicine, London, UK. ${ }^{6}$ Department of Health Sciences, University of Groningen, University Medical Center Groningen, Groningen, The 
Netherlands. ${ }^{7}$ Department of Economics, Econometrics \& Finance, University of Groningen, Faculty of Economics \& Business, Groningen, The Netherlands.

\section{Received: 5 July 2018 Accepted: 9 November 2018 Published online: 06 December 2018}

\section{References}

1. Cohen J. Herpes zoster. N Engl J Med. 2013;369(18):1766-7.

2. van Lier A, Smits G, Mollema L, Waaijenborg S, Berbers G, van der Klis F, Boot $\mathrm{H}$, Wallinga J, de Melker $\mathrm{H}$. Varicella zoster virus infection occurs at a relatively young age in the Netherlands. Vaccine. 2013;31(44):5127-33.

3. National Institute for Public Health and the Environment. In: Schurink-van 't Klooster TM, de Melker $\mathrm{H}$, editors. The National Immunisation Programme in the Netherlands. Bilthoven: surveillance and developments in 2016-2017; 2017.

4. Schroder C, Enders D, Schink T, Riedel O. Incidence of herpes zoster amongst adults varies by severity of immunosuppression. J Inf Secur. 2017; 75(3):207-15.

5. Melegaro A, Marziano V, Del Fava E, Poletti P, Tirani M, Rizzo C, Merler S. The impact of demographic changes, exogenous boosting and new vaccination policies on varicella and herpes zoster in Italy: a modelling and cost-effectiveness study. BMC Med. 2018;16(1):117.

6. van Wijck AJM, Aerssens YR. Pain, itch, quality of life, and costs after herpes zoster. Pain Pract. 2017;17(6):738-46.

7. Opstelten W, Mauritz JW, de Wit NJ, van Wijck AJ, Stalman WA, van Essen GA. Herpes zoster and postherpetic neuralgia: incidence and risk indicators using a general practice research database. Fam Pract. 2002;19(5):471-5.

8. Helgason S, Petursson G, Gudmundsson S, Sigurdsson JA. Prevalence of postherpetic neuralgia after a first episode of herpes zoster: prospective study with long term follow up. BMJ. 2000;321(7264):794-6.

9. Johnson RW, Wasner G, Saddier P, Baron R. Postherpetic neuralgia: epidemiology, pathophysiology and management. Expert Rev Neurother. 2007:7(11):1581-95.

10. European Medicines Agency. Zostavax: EPAR - Product Information 2009 https://www.ema.europa.eu/documents/product-information/zostavax-eparproduct-information_en.pdf. Accessed at 1 Oct 2018.

11. Oxman MN, Levin MJ, Johnson GR, Schmader KE, Straus SE, Gelb LD, Arbeit RD, Simberkoff MS, Gershon AA, Davis LE, et al. A vaccine to prevent herpes zoster and postherpetic neuralgia in older adults. N Engl J Med. 2005; 352(22):2271-84

12. Morrison VA, Johnson GR, Schmader KE, Levin MJ, Zhang JH, Looney DJ, Betts R, Gelb L, Guatelli JC, Harbecke R, et al. Long-term persistence of zoster vaccine efficacy. Clin Infect Dis. 2015;60(6):900-9.

13. Health council of the Netherlands. Vaccination against shingles [In Dutch]; 2016. https://www.gezondheidsraad.nl/documenten/adviezen/2016/06/29/ vaccinatie-tegen-gordelroos. Accessed 1 Sept 2018.

14. Izurieta HS, Wernecke M, Kelman J, Wong S, Forshee R, Pratt D, Lu Y, Sun Q, Jankosky C, Krause $P$, et al. Effectiveness and duration of protection provided by the live-attenuated herpes zoster vaccine in the Medicare population ages 65 years and older. Clin Infect Dis. 2017;64(6):785-93.

15. Baxter R, Bartlett J, Fireman B, Marks M, Hansen J, Lewis E, Aukes L, Chen Y, Klein NP, Saddier P. Long-term effectiveness of the live zoster vaccine in preventing shingles: a cohort study. Am J Epidemiol. 2018;187(1):161-9.

16. Tseng HF, Harpaz R, Luo Y, Hales CM, Sy LS, Tartof SY, Bialek S, Hechter RC, Jacobsen SJ. Declining effectiveness of herpes zoster vaccine in adults aged $\geq 60$ years. J Infect Dis. 2016;213(12):1872-5.

17. Marin M, Yawn BP, Hales CM, Wollan PC, Bialek SR, Zhang J, Kurland MJ, Harpaz R. Herpes zoster vaccine effectiveness and manifestations of herpes zoster and associated pain by vaccination status. Hum Vaccin Immunother. 2015;11(5):1157-64.

18. European Medicines Agency. Shingrix: EPAR - Product Information 2018 https://www.ema.europa.eu/documents/product-information/shingrix-eparproduct-information_en.pdf. Accessed at 1 Oct 2018.

19. Lal H, Cunningham AL, Godeaux O, Chlibek R, Diez-Domingo J, Hwang SJ, Levin MJ, McElhaney JE, Poder A, Puig-Barbera J, et al. Efficacy of an adjuvanted herpes zoster subunit vaccine in older adults. N Engl J Med. 2015;372(22):2087-96.

20. Cunningham AL, Lal H, Kovac M, Chlibek R, Hwang SJ, Diez-Domingo J, Godeaux O, Levin MJ, McElhaney JE, Puig-Barbera J, et al. Efficacy of the herpes zoster subunit vaccine in adults 70 years of age or older. N Engl J Med. 2016;375(11):1019-32
21. Le $P$, Rothberg MB. Cost-effectiveness of the adjuvanted herpes zoster subunit vaccine in older adults. JAMA Intern Med. 2018;178(2):248-258.

22. Van Oorschot D, Anastassopoulou A, Poulsen Nautrup B, Varghese L, von Krempelhuber A, Neine M, Lorenc S, Curran D. Cost-effectiveness of the recombinant zoster vaccine in the German population aged $\geq 60$ years old. Hum Vaccin Immunother. 2018:21:1-11.

23. You JHS, Ming WK, Lee CF, Tsang OT, Chan PK. Potential cost-effectiveness of adjuvanted herpes zoster subunit vaccine for older adults in Hong Kong. Vaccine. 2018;36(31):4610-20

24. Curran D, Patterson B, Varghese L, Van Oorschot D, Buck P, Carrico J, Hicks K, Lee B, Yawn B. Cost-effectiveness of an adjuvanted recombinant zoster vaccine in older adults in the United States. Vaccine. 2018;36(33):5037-45.

25. National Health Care Institute. Cost-effectiveness in practice [In Dutch]; 2015 https://www.zorginstituutnederland.nl/binaries/zinl/documenten/rapport/ 2015/06/26/kosteneffectiviteit-in-de-praktijk/Kosteneffectiviteit+in+de +praktijk.pdf. Accessed 1 Sept 2018

26. Levin MJ, Schmader KE, Pang L, Williams-Diaz A, Zerbe G, Canniff J, Johnson MJ, Caldas Y, Cho A, Lang N, et al. Cellular and humoral responses to a second dose of herpes zoster vaccine administered 10 years after the first dose among older adults. J Infect Dis. 2016;213(1):14-22.

27. National Health Care Institute. Guideline for economic evaluations in healthcare 2016 https://english.zorginstituutnederland.nl/publications/ reports/2016/06/16/guideline-for-economic-evaluations-in-healthcare. Accessed at 1 Dec 2017

28. Statistics Netherlands. Life-expectancy; gender, age (per year and period of five years); 2017. http://statline.cbs.nl/Statweb/publication/?DM=SLNL\&PA= 37360ned \&D1 =0\&D2=0\&D3=a\&D4=94-95\%2cl\&HDR=G1\%2cT\&STB= G2\%2cG3\&WW=T. Accessed 1 Dec 2017

29. Statistics Netherlands. Population; gender, age, marital status and region, January 2017. http://statline.cbs.nl/Statweb/publication/?DM=SLNL\&PA= 03759ned\&D1 $=0-2 \& D 2=0-117 \& D 3=0 \& D 4=\mid \& H D R=T \& S T B=G 2, G 3, G 1 \& W W=T$. Accessed 1 Dec 2017

30. Netherlands Institute for Health Services Research (NIVEL). NIVEL healtcare registrations first line 2017 https://www.nivel.nl/nl/nzr/zorgregistratieseerstelijn. Accessed at 1 Dec 2017.

31. van Hoek AJ, Gay N, Melegaro A, Opstelten W, Edmunds WJ. Estimating the cost-effectiveness of vaccination against herpes zoster in England and Wales. Vaccine. 2009;27(9):1454-67.

32. Dutch Hospital Data (DHD). Landelijke basisregistratie ziekenhuiszorg (LBZ) [Dutch national registration hospital care] 2017 https://www.dhd.nl/ producten-diensten/LBZ/Paginas/Dataverzameling-LBZ.aspx. Accessed at 1 Dec 2017.

33. Beninca $E$, van Boven M, Hagenaars T, van der Hoek W. Space-time analysis of pneumonia hospitalisations in the Netherlands. PLoS One. 2017:12(7):e0180797.

34. Statistics Netherlands. Deceased; cause of death (extended list), age, gender 2017. http://statline.cbs.n//Statweb/publication/?DM $=S L N L \& P A=7233 \& D 1=$ 90\&D2=0\&D3=12-21\&D4=13-20\&HDR=G2\%2cG1\%2cG3\&STB=T\&W=T Accessed 1 Dec 2017.

35. Mahamud A, Marin M, Nickell SP, Shoemaker T, Zhang JX, Bialek SR. Herpes zoster-related deaths in the United States: validity of death certificates and mortality rates, 1979-2007. Clin Infect Dis. 2012;55(7):960-6.

36. Szende A, Janssen B, Cabases J. Self-reported population health: an international perspective based on EQ-5D: Springer Open; 2014. https://link. springer.com/content/pdf/10.1007\%2F978-94-007-7596-1.pdf. Accessed 1 Sept 2018.

37. Statistics Netherlands. Consumer prices; price index 2015=100 2017 http://statline.cbs.nl/Statweb/publication/?DM=SLEN\&PA=83131ENG\&D1= 0\&D2 $=0 \& D 3=64,77,90,103,116,129,142,155,168,181,194,207,220,233,246$ 259,272,285\&LA=EN\&HDR=T\&STB=G1,G2\&VW=T. Accessed 1 Dec 2017.

38. Hakkaart-van Roijen L, Tan SS, Bouwmans CAM. Guidance for costing research; methods and standardized prices for economic evaluations in health care [In Dutch]; 2010. https://docplayer.nl/6361834-Handleiding-voorkostenonderzoek-methoden-en-standaard-kostprijzen-voor-economischeevaluaties-in-de-gezondheidszorg.html. Accessed 1 Sept 2018.

39. Versteegh $M$, Knies S, Brouwer W. From good to better: new Dutch guidelines for economic evaluations in healthcare. Pharmacoeconomics. 2016:34(11):1071-4

40. van Baal PH, Wong A, Slobbe LC, Polder JJ, Brouwer WB, de Wit GA Standardizing the inclusion of indirect medical costs in economic evaluations. Pharmacoeconomics. 2011;29(3):175-87. 
41. Stichting Nationaal Programma Grieppreventie (SNPG). Fee (In Dutch); 2017. https://www.snpg.nl/article/declareren-griepvaccinaties/vergoeding/. Accessed at 1 Dec 2017.

42. Eilers $\mathrm{R}$, de Melker HE, Veldwijk J, Krabbe PFM. Vaccine preferences and acceptance of older adults. Vaccine. 2017;35(21):2823-30.

43. Mangen MJ, Rozenbaum MH, Huijts SM, van Werkhoven $\mathrm{CH}$, Postma DF Atwood M, van Deursen AM, van der Ende A, Grobbee DE, Sanders EA, et al. Cost-effectiveness of adult pneumococcal conjugate vaccination in the Netherlands. Eur Respir J. 2015:46(5):1407-16.

44. Schmader KE, Levin MJ, Gnann JW Jr, McNeil SA, Vesikari T, Betts RF, Keay S, Stek JE, Bundick ND, Su SC, et al. Efficacy, safety, and tolerability of herpes zoster vaccine in persons aged 50-59 years. Clin Infect Dis. 2012;54(7):922-8

45. Rohan P. FDA Clinical Briefing Document for Merck \& Co., Inc. Zoster vaccine live (Oka/Merck) Zostavax ${ }^{\mathrm{TM}}$; 2005. http://citeseerx.ist.psu.edu/ viewdoc/download?doi=10.1.1.177.2250\&rep=rep1\&type=pdf. Accessed 1 Dec 2017.

46. Schmader KE, Oxman MN, Levin MJ, Johnson G, Zhang JH, Betts R, Morrison VA, Gelb L, Guatelli JC, Harbecke R, et al. Persistence of the efficacy of zoster vaccine in the shingles prevention study and the short-term persistence substudy. Clin Infect Dis. 2012;55(10):1320-8.

47. Curran D, Van Oorschot D, Varghese L, Oostvogels L, Mrkvan T, Colindres R, von Krempelhuber A, Anastassopoulou A. Assessment of the potential public health impact of herpes zoster vaccination in Germany. Hum Vaccin Immunother. 2017;13(10):2213-21.

48. Rozenbaum MH, Sanders EA, van Hoek AJ, Jansen AG, van der Ende A, van den Dobbelsteen G, Rodenburg GD, Hak E, Postma MJ. Cost effectiveness of pneumococcal vaccination among Dutch infants: economic analysis of the seven valent pneumococcal conjugated vaccine and forecast for the 10 valent and 13 valent vaccines. BMJ. 2010;340:c2509.

49. Hobbelen PH, Stowe J, Amirthalingam G, Miller L, van Hoek AJ. The burden of hospitalisation for varicella and herpes zoster in England from 2004 to 2013. J Inf Secur. 2016;73(3):241-53.

50. Walker JL, Andrews NJ, Amirthalingam G, Forbes H, Langan SM, Thomas SL. Effectiveness of herpes zoster vaccination in an older United Kingdom population. Vaccine. 2018.

51. Husereau D, Drummond M, Petrou S, Carswell C, Moher D, Greenberg D, Augustovski F, Briggs AH, Mauskopf J, Loder E, et al. Consolidated Health Economic Evaluation Reporting Standards (CHEERS) statement. BMJ. 2013; 346:f1049.

52. Vemer P, Corro Ramos I, Van Voorn G, Al MJ, Feenstra TL. AdVISHE: a new tool to report validation of health-economic decision models. Value Health. 2014;17(7):A556-7.

53. Centers for Disease Control and Prevention. Adult Vaccine Price List 2018 https://www.cdc.gov/vaccines/programs/vfc/awardees/vaccine-management /price-list/index.html. Accessed at 1 Oct 2018.

54. National Health Care Institute. Medicijnkosten.nl 2017 www.medicijnkosten. nl. Accessed at 1 Dec 2017

55. Langan SM, Smeeth L, Margolis DJ, Thomas SL. Herpes zoster vaccine effectiveness against incident herpes zoster and post-herpetic neuralgia in an older US population: a cohort study. PLoS Med. 2013; 10(4):e1001420.

56. Levin MJ, Buchwald UK, Gardner J, Martin J, Stek JE, Brown E, Popmihajlov Z. Immunogenicity and safety of zoster vaccine live administered with quadrivalent influenza virus vaccine. Vaccine. 2018;36(1):179-85.

57. Schwarz TF, Aggarwal N, Moeckesch B, Schenkenberger I, Claeys C, Douha M, Godeaux O, Grupping K, Heineman TC, Fauqued ML, et al. Immunogenicity and safety of an adjuvanted herpes zoster subunit vaccine coadministered with seasonal influenza vaccine in adults aged 50 years or older. J Infect Dis. 2017;216(11):1352-61.

58. Lal H, Poder A, Campora L, Geeraerts B, Oostvogels L, Vanden Abeele C, Heineman TC. Immunogenicity, reactogenicity and safety of 2 doses of an adjuvanted herpes zoster subunit vaccine administered 2, 6 or 12 months apart in older adults: results of a phase III, randomized, open-label, multicenter study. Vaccine. 2018;36(1):148-54.

59. Dooling KL, Guo A, Patel M, Lee GM, Moore K, Belongia EA, Harpaz R. Recommendations of the Advisory Committee on Immunization Practices for Use of Herpes Zoster Vaccines. MMWR Morb Mortal Wkly Rep. 2018;67(3):103-8.

60. Cohen J. Strategies for herpes zoster vaccination of immunocompromised patients. J Infect Dis. 2008;197(Suppl 2):S237-41.
61. Health Council of the Netherlands. The individual, collective and public relevance of vaccination; 2013. https://www.gezondheidsraad.nl/over-ons/ documenten/adviezen/2013/10/03/het-individuele-collectieve-en-publiekebelang-van-vaccinatie. Accessed 1 Sept 2018.

62. National Health Service. Shingles vaccination 2015 https://www.nhs.uk/ Conditions/vaccinations/Pages/shingles-vaccination.aspx. Accessed at 1 Dec 2017.

63. Immunisation and High Consequence Infectious Diseases Team GaPHG Consultation on the Cost-Effectiveness Methodology for Vaccination Programmes and Procurement (CEMIPP) Report 2018 https://assets. publishing.service.gov.uk/government/uploads/system/uploads/attachment data/file/683841/Consultation_document_re_CEMIPP.pdf. Accessed at 1 June 2018.

64. Pinchinat S, Cebrian-Cuenca AM, Bricout H, Johnson RW. Similar herpes zoster incidence across Europe: results from a systematic literature review. BMC Infect Dis. 2013;13:170.

65. Le P, Rothberg MB. Cost-effectiveness of the recommendations of the Advisory Committee on Immunization Practices for the recombinant adjuvanted zoster subunit vaccine. JAMA Intern Med. 2018;178(9):1277-8.

66. van Lier A, van Hoek AJ, Opstelten W, Boot HJ, de Melker HE. Assessing the potential effects and cost-effectiveness of programmatic herpes zoster vaccination of elderly in the Netherlands. BMC Health Serv Res. 2010;10:237.

67. de Boer PT, Pouwels KB, Cox JM, Hak E, Wilschut JC, Postma MJ. Costeffectiveness of vaccination of the elderly against herpes zoster in the Netherlands. Vaccine. 2013;31(9):1276-83.

68. ClinicalTrials.gov. A long-term follow-up study (ZOE-LTFU) of two studies 110390 (ZOSTER-006) and 113077 (ZOSTER-022) to assess the efficacy, safety, and immunogenicity persistence of GSK biologicals' herpes zoster subunit ( $\mathrm{HZ} / \mathrm{su})$ vaccine and assessment of 1 or 2 additional doses in two subgroups of older adults 2016 https://linicaltrials.gov/ct2/show/ NCT02723773? cond=hz\%2Fsu\&rank=6. Accessed at 1 Dec 2017.

69. GSK. New data supports the safety and efficacy of GSK's Shingrix in preventing shingles in autologous haematopoietic stem cell transplant patients 2017 https://www.gsk.com/en-gb/media/press-releases/new-datasupports-the-safety-and-efficacy-of-gsk-s-shingrix-in-preventing-shingles-inautologous-haematopoietic-stem-cell-transplant-patients/. Accessed at 15 Jan 2017.

70. Rogers JE, Cumpston A, Newton M, Craig M. Onset and complications of varicella zoster reactivation in the autologous hematopoietic cell transplant population. Transpl Infect Dis. 2011;13(5):480-4.

\section{Ready to submit your research? Choose BMC and benefit from:}

- fast, convenient online submission

- thorough peer review by experienced researchers in your field

- rapid publication on acceptance

- support for research data, including large and complex data types

- gold Open Access which fosters wider collaboration and increased citations

- maximum visibility for your research: over $100 \mathrm{M}$ website views per year

At BMC, research is always in progress.

Learn more biomedcentral.com/submissions 